\title{
El régimen jurídico de la prevención ambiental en la Comunidad de Castilla y León
}

\author{
Dionisio Fernández de Gatta Sánchez \\ Profesor Titular de Derecho Administrativo. Facultad de Derecho \\ Prof. de Legislación Ambiental. Facultad de Ciencias Agrarias \\ y Ambientales y de Biología. Universidad de Salamanca \\ Diplomado en Ciencias Ambientales \\ Vocal del Observatorio Español de Políticas Ambientales
}

\begin{abstract}
Sumario: I. INTRODUCCIÓN. EL SURGIMIENTO DE LA PROBLEMÁTICA AMBIENTAL. EL DERECHO AMBIENTAL Y SU FUNCIÓN PROTECTORA. LOS PROBLEMAS DE LOS ENFOQUES SECTORIALES EN LA PROTECCIÓN DEL MEDIO AMBIENTE. A) El surgimiento de la problemática ambiental. El Derecho Ambiental y su función protectora del medio ambiente. B) Los problemas de los enfoques sectoriales en la protección ambiental. II) LA PREVENCIÓN AMBIENTAL Y EL CONTROL INTEGRADO DE LA CONTAMINACIÓN EN LA UNIÓN EUROPEA. A) Aspectos generales. B) La Directiva 96/61/CE, del Consejo, de 24 de septiembre de 1996, relativa a la Prevención y al Control Integrados de la Contaminación. III) LA LEGISLACIÓN ESPAÑOLA SOBRE PREVENCIÓN AMBIENTAL Y CONTROL INTEGRADO DE LA CONTAMINACIÓN. A) La intervención administrativa en la industria: aspectos generales e históricos. B) La incidencia de la Constitución Española de 1978. C) La Ley de Prevención y Control Integrados de la Contaminación de 2002. IV. LAS COMPETENCIAS Y LA LEGISLACIÓN DE LA COMUNIDAD DE CASTILLA Y LEÓN SOBRE PREVENCIÓN Y CONTROL INTEGRADO DE LA CONTAMINACIÓN. A) Las competencias de la Comunidad de Castilla y León sobre medio ambiente. B) El primer sistema preventivo de intervención ambiental en la Comunidad: la Ley de Actividades Clasificadas de 1993 y sus normas de desarrollo. C) El modelo actual de prevención ambiental y de control integrado de la contaminación en la Comunidad de Castilla y León: la Ley de Prevención Ambiental de 2003 y sus normas de desarrollo. 1) Aspectos generales, ámbito de aplicación y sistema administrativo de prevención ambiental. 2) El régimen jurídico de la Autorización Ambiental (arts. 10 a 23). 3) El sistema de la Licencia Ambiental (arts. 24 a 32). 4) Disposiciones comunes a la autorización ambiental y a la licencia ambiental (arts. 33 a 44). 5) El régimen de las Evaluaciones de Impacto Ambiental (arts. 45 a 57). 6) El novedoso sistema de Comunicación Ambiental (art. 58). 7) El régimen de control, de inspección y sancionador (arts. 59 a 68 y 73 a 88). 8) Las Comisiones de Prevención Ambiental (arts. 69 a 72). 9) El régimen excepcional de las actividades ganaderas en Castilla y León. BIBLIOGRAFÍA BÁSICA.
\end{abstract}




\section{INTRODUCCIÓN. EL SURGIMIENTO DE LA PROBLEMÁTICA AMBIENTAL. EL DERECHO AMBIENTAL Y SU FUNCIÓN PROTECTORA. LOS PROBLEMAS DE LOS ENFOQUES SECTORIALES EN LA PROTECCIÓN DEL MEDIO AMBIENTE}

\section{A) EI surgimiento de la problemática ambiental. EI Derecho Ambiental y su función protectora del medio ambiente}

En la actualidad existe preocupación pública e institucional por el estado del medio ambiente. Aunque el origen de este interés es anterior al siglo XIX, experimentó un enorme desarrollo después de la II Guerra Mundial. En cualquier caso, y sin perjuicio de ciertas corrientes críticas, parece que la percepción y valoración social sobre los problemas ambientales ha cambiado drásticamente hacia posiciones de mayor preocupación, siendo cierto que esta mayor preocupación está más presente en la moderna conciencia ciudadana, y que evoluciona con el paso del tiempo, aunque no falten posiciones críticas con esta concepción.

Teniendo el Derecho, en general, como objetivos amplios la ordenación de las relaciones sociales y de la vida social, la dirección de las sociedades hacia determinados valores y la resolución de conflictos, cuando los ciudadanos y los Poderes Públicos son conscientes de la situación y de los problemas ambientales, destacando su importancia para el interés general (en última instancia, y sin ser catastrofistas, la salvaguardia del Planeta y de la Humanidad), el medio ambiente se convierte en un bien jurídico a proteger y en objeto de regulación por el Ordenamiento Jurídico; surgiendo así el Derecho Ambiental, entendiendo por tal, siguiendo a MARTín MATEO, el sistema normativo que trata de proteger el medio ambiente y los elementos que permiten la vida, y que constituye la respuesta de la sociedad a la necesidad de proporcionar tal protección para evitar la degradación progresiva del medio natural y de dichos elementos.

Así, desde los años 70 del siglo xx, con carácter general, el medio ambiente se protege por normas jurídicas destinadas específicamente a esta función, existiendo actualmente diversos Ordenamientos (principalmente, internacional, europeo, estatal, autonómico y local) y Poderes Públicos (en particular, Administraciones Públicas) que desarrollan estas funciones tutelares del medio ambiente y de los recursos naturales. Es más, la consideración de los problemas ambientales como cuestiones que afectan al interés general provocará que la protección del medio ambiente sea considerada, desde estos mismos años, como una función pública; y, en particular, de las Administraciones Públicas.

Esta función protectora del medio ambiente que lleva a cabo el Ordenamiento Jurídico no se realiza de cualquier forma, sino que ha de partir del 
concepto de «calidad de vida» como aspiración situada en primer plano por el Preámbulo de la Constitución Española de 1978 (STC 102/1995, de 26 de junio, $\mathrm{FJ} \mathrm{n}^{\circ} 4$ ), y que tiene dos ejes principales: el desarrollo y progreso económico y social (basado en la libertad de empresa, en el marco de la economía de mercado, y sin perjuicio de preverse la intervención pública en ésos ámbitos) y la preservación del medio ambiente y del sistema natural (que constituye título habilitante y obligación, al mismo tiempo, para la intervención del Derecho y de los Poderes Públicos). Siendo, así, necesario, pues, compatibilizar y armonizar estos dos ejes, tal como señala la STC 64/1982, de 4 de noviembre,

«...no puede considerarse como objetivo primordial y excluyente la explotación al
máximo de los recursos naturales, el aumento de la producción a toda costa, sino
que se ha de armonizar la 'utilización racional' de ésos recursos con la protección
de la naturaleza, todo ello para el mejor desarrollo de la persona y para asegurar
una mejor calidad de vida...»(FJ $\left.\mathrm{n}^{\circ} 2\right)$.

Se trataría, de este modo, de intentar alcanzar el «desarrollo sostenible», equilibrado y racional que no olvida las generaciones futuras, como señala la STC 102/1995, de 26 de junio ( $\mathrm{FJ} \mathrm{n}^{\mathrm{o}} 4$ ), con mención expresa al contenido del informe BRUNDTLAND, «Nuestro futuro común», de 1987.

Modelo, éste, que está previsto en la Constitución Española y, en el ámbito europeo, tanto en el Tratado de la Unión Europea y en el Tratado de la Comunidad Europea, según los textos vigentes después de la reforma realizada por el Tratado de Niza, de 2001-2003, como en el Tratado por el que se establece una Constitución para Europa, de 29 de octubre de 2004 (que aún no ha sido aprobado).

Además, como hemos señalado, debe tenerse en cuenta la esencial intervención de los Poderes Públicos y, en particular, de las Administraciones Públicas en la protección del medio ambiente. Así, esta nueva perspectiva señalada le dará al Derecho Ambiental un eminentemente carácter público, al derivar la misma de la percepción de que tal protección ambiental es una exigencia de la supervivencia humana, ya que los recursos naturales son escasos, y, por ello, se requiere un uso racional de los mismos. Es más, en ésa preservación del medio ambiente debe tenerse en cuenta no sólo el presente sino también las generaciones futuras, con la finalidad de permitirles vivir en condiciones adecuadas de habitabilidad y de calidad de vida; es decir, tener en cuenta el concepto del desarrollo sostenible.

Debido a las razones anteriores, las legislaciones de esta época comienzan a atribuir globalmente la función de corregir y hacer disminuir la degradación ambiental a los Poderes Públicos y, en particular, a las Administraciones Públicas, por los intereses generales implicados, como hemos señalado. Ya no es suficiente, como en el pasado, la mera presencia de una reducida 
Administración que garantiza unas correctas relaciones de vecindad y protege la salubridad pública. En la actualidad, la protección del medio ambiente de los variados y agresivos agentes contaminantes requiere una acción pública eficaz y diversificada, debido al origen y contenido de los peligros y riesgos ambientales. Se requiere, pues, una directa intervención pública ordenando, inspeccionando y sancionando las conductas humanas, es decir, utilizando el poder de autoridad, ya que el mercado no protege el medio ambiente, sino que, más bien, lo deteriora.

Así, esta novedosa concepción, hoy generalizada, está garantizada en el Tratado de la Unión Europea, en el Tratado por el que se establece una Constitución para Europa y en el art. 45-2 ${ }^{\circ}$ de la Constitución Española de 1978, al señalar éste último que

«Los poderes públicos velarán por la utilización racional de todos los recursos naturales, con el fin de proteger y mejorar la calidad de la vida y defender y restaurar el medio ambiente, apoyándose en la indispensable solidaridad colectiva».

Las tareas encomendadas a las Administraciones Públicas por el Ordenamiento Jurídico pueden llevarse a cabo de múltiples y variadas formas. Entre los modos de actuación administrativa más comunes se suelen mencionar la actividad de policía o de limitación, la actuación de fomento o estimulante, la actividad de prestación o de servicio público y la actividad o gestión económica. En el desempeño de estas actividades, la Administración Pública ejercita potestades, entendiendo por tales los poderes jurídicos, reconocidos por el Ordenamiento, susceptibles de ser aplicados con carácter permanente a quienes se encuentren sometidos a la acción de la Administración, y cuyo ejercicio corresponde en exclusiva a ésta. Además, estas modalidades de actuación administrativa pueden contemplarse desde la perspectiva de la responsabilidad que asumen las Administraciones Públicas, o, incluso, los funcionarios y el personal que las integra, como consecuencia de su actuación, o de su falta, cuando están obligadas a ello, y causan daño.

\section{B) Los problemas de los enfoques sectoriales en la protección ambiental}

El impacto negativo de las actividades humanas sobre el medio ambiente y los recursos naturales, a pesar de no ser un fenómeno de nuestro tiempo, como es sabido, generado, principalmente, por la Revolución Industrial (siglo XVIII) y, en particular, debido al trascendental desarrollo económico producido en Europa y en los Estados Unidos después de la II Guerra Mundial, se traduce en la alteración sin precedentes de los ciclos naturales fundamentales y de las condiciones de evolución de la Tierra, es decir, el deterioro del equilibrio ecológico por la aparición de procesos de contaminación 
cada vez más graves y la afectación (e, incluso, agotamiento, si bien no inmediato) a los recursos naturales, produciendo, en fin, un apreciable desequilibrio entre el medio natural y las demandas que la humanidad le solicita. Esta preocupación, hoy día generalizada, que comienza, primero tímidamente, en los años 60 y 70 del siglo Xx, y se hace más amplia en los años 80 , se traduce en la intervención del Derecho, integrando la protección ambiental y de la naturaleza como objeto y bien (jurídico) a proteger y alcanzar.

Sin embargo, esta intervención del Ordenamiento Jurídico no ha sido, ni es, en el tiempo, homogénea en cuanto a los objetivos, ni ha utilizado siempre una única gama de instrumentos. En efecto, los modelos económico-productivos de los años 50 a 70 del siglo XX eran, como es sabido, muy contaminantes, afectando fuertemente a los recursos naturales, creando, y haciendo necesarias, de forma inmediata y urgente, las medidas jurídicas «curativas», principalmente, durante los procesos de contaminación y deterioro ambiental, intentando mantenerlos en niveles «admisibles», mediante normas fijándolos, y posteriormente a dichos procesos de contaminación, incumpliendo las normativas anteriores, mediante las normas sancionadoras administrativas y penales y las relativas a la responsabilidad por el daño ambiental causado. Es decir, se actúa cuando un peligro era evidente o cuando el daño ya se había realizado.

El modelo económico de los años $80 \mathrm{y}$, sobre todo, en los 90, parte, sin embargo, en términos generales de la compatibilidad entre el desarrollo socioeconómico y la protección ambiental, que es la idea directriz reflejada en el concepto de «desarrollo sostenible»; es decir, se trataría de lograr que la relación entre la economía y el medio ambiente sea positiva (en línea con lo precisado por el Libro Blanco sobre Crecimiento, Competitividad y Empleo, de la Comisión Europea, de 1993). Por ello, sin abandonarse las medidas ambientales «curativas», pues los procesos de contaminación continúan existiendo, se comienzan a utilizar con carácter general instrumentos preventivos, tratando de proteger el medio ambiente, evitando los procesos de contaminación, o, al menos, minimizándolos.

El variado conjunto de normas e instrumentos que hemos denominado «curativos» fueron, y son, muy importantes, debido a la persistencia de los procesos contaminantes y al impacto en la naturaleza, pero tienen carácter aislado y parcial, en particular porque son instrumentos y medidas sectoriales.

En efecto, debido a la urgencia y a la necesidad imperiosa de hacer frente a las contaminaciones, en gran parte debido a la concienciación de los ciudadanos y de los Poderes Públicos, se comienzan a tomar medidas con relación a los medios más afectados por los procesos industriales, en general, de la actividad humana, que inicialmente son el aire y el agua, y otras sobre las fuentes de contaminación de los mismos; son, pues, medidas parciales no basadas en los conceptos ecológicos. Pero, además, ha de tenerse en cuenta que se utilizan instrumentos sectoriales, aún en esos mismos medios, basa- 
dos habitualmente en la clásica forma de actuar de la Administración Pública: supervisión y control, inspección y sanción; aplicados materialmente en cuanto a los productos y procesos de producción, fijando objetivos o estándares obligatorios y de calidad, o normas de emisión; normas sobre procedimientos y aspectos documentales; normas de fomento, etc.; teniendo en cuenta, además, que estas normas se aplican y hacen cumplir por varios órganos y Administraciones Públicas.

La aplicación de estas medidas e instrumentos no tuvo en cuenta, primero, que algunos procesos de contaminación afectan, no sólo al medio en el que se está actuando, sino a otros o a todos, y, segundo, que el carácter parcial y sectorial de estas medidas impedían, incluso, solucionar algunos problemas en un único medio en el que se actuara.

Además, se comienzan a poner en duda las medidas «curativas», y su eficacia, en la protección ambiental, ya que a veces no es posible restituir la situación del medio al momento anterior a la agresión o deterioro, o dicha restitución es muy costosa; las secuelas ambientales de estas agresiones, muchas veces, son graves e, incluso, irreversibles. Por otro lado, tales medidas no eran adecuadas ante riesgos incalculables y falta o insuficiencia de conocimientos científicos.

Esto provoca que, en particular desde los años 80 del siglo XX, aunque hay antecedentes anteriores, se pongan en marcha instrumentos preventivos, tendentes a evitar las contaminaciones, e integradores, en cuanto a la intervención teniendo en cuenta la incidencia en todos los medios y los instrumentos utilizables. Mediante ellos, se reduce a unidad la regulación de los distintos sectores ambientales, heterogéneos y frecuentemente desconectados, y se trata, asimismo, de llevar a la unidad la actuación de los diversos órganos y Administraciones Públicas competentes en la materia.

En este contexto, la Directiva 96/61/CE, del Consejo de 24 de septiembre de 1996, y las normas de transposición de la misma de los Estados Miembros, tratan de hacer frente a ambas cuestiones y objetivos: la prevención y el control integrados de la contaminación; significando, sin duda, un punto de inflexión en la Política Ambiental Comunitaria y en la concepción normativa del medio ambiente, tanto desde el punto de vista cualitativo como conceptual.

A pesar de que la prevención y el control integrados de la contaminación parecen cuestiones obvias desde el punto de vista ambiental, han sido un permanente problema, aún no resuelto, para la aplicación de las políticas ambientales, tanto desde el punto de vista administrativo (pues, las competencias públicas estaban, y están aún, muy dispersas) como de la propia industria, que siempre ha tenido problemas para determinar claramente las responsabilidades derivadas de la normativa, debido a su carácter sectorial y parcial. 
La Directiva trata, como veremos, de paliar estos problemas, haciendo más efectivos tanto el Derecho Ambiental como la actividad de los Poderes Públicos responsables de la protección ambiental, e incluso incidiendo en el ámbito privado; inicia un nuevo enfoque en materia ambiental, que parece el más adecuado para resolver tales problemas, y será un marco de referencia obligado para el futuro, con evidentes repercusiones en las legislaciones ambientales de los Estados Miembros. Por ello, sin duda, implicará esfuerzos, y no precisamente de poca entidad, tanto por parte de las industrias implicadas como de las Administraciones responsables de la elaboración de las normas de transposición, y de su aplicación.

\section{II) LA PREVENCIÓN AMBIENTAL Y EL CONTROL INTEGRADO DE LA CONTAMINACION EN LA UNIÓN EUROPEA}

\section{A) Aspectos generales}

A pesar de que se puedan detectar instrumentos horizontales de lucha contra el deterioro ambiental, en general la legislación, tanto en relación con los medios como con las fuentes de las contaminaciones, y la organización de la Administración Pública, al existir diversos órganos con competencias diferentes, han tenido, y aún a veces tienen, un marcado carácter sectorial y parcial.

La Comunidad Europea también ha seguido este modelo, hasta los años 80 del siglo XX, pues la primera generación de normas ambientales europeas se caracterizó por un planteamiento sectorial. Así, desde los años 70, e incluso antes, principalmente, la Comunidad Europea se dedicó a legislar en materia de contaminación atmosférica y de las aguas, al ser los medios más afectados por el deterioro ambiental; en particular, utilizando normas reguladoras de los productos (gasolinas, vehículos; detergentes, etc.) y de los procesos de producción (instalaciones industriales, centrales energéticas, incineradoras municipales, etc.), siendo muy comunes las normas fijando tanto los objetivos y estándares obligatorios como los de calidad (así, se establecen los parámetros máximos de contaminación que el aire o el agua deben tener, siendo ilegal sobrepasarlos, si bien eluden la identificación de las fuentes y no suelen hacer referencia a los procedimientos para conseguir los objetivos de calidad), completadas con normas de emisión (muy apropiadas para controlar la contaminación puntual). Un poco más tarde comenzaría a preocuparse del suelo, al legislar en materia de residuos, aunque de forma parcial.

Esta abundante normativa, relativa a los medios o a las fuentes específicas de la contaminación y a las funciones de las Administraciones Públicas, provoca que comience a ponerse en duda, sobre todo en los años 80 , la efec- 
tividad de estos métodos de lucha, en particular porque no se tenían en cuenta ni se evitaban que los niveles de contaminación pudieran aumentar en otros medios naturales, o, incluso, en el mismo medio afectado, si el instrumento sobre la fuente de la contaminación no era suficiente. Es decir, las sustancias contaminantes no desaparecían sino que se trasladaban de lugar, en el mismo medio, o había transferencia de contaminación a otro medio distinto. Por esto, la Comunidad Europea comenzará a utilizar instrumentos preventivos a partir de estos años.

Así pues, la insuficiencia de los instrumentos jurídicos, utilizados con carácter general en los años 60 y 70, e incluso hoy pues siguen siendo necesarios, basados en paliar las consecuencias de la contaminación y en imputar un sistema de responsabilidades disuasorio de actuaciones negativas, hará surgir una segunda generación de políticas de protección ambiental basadas en integrar las actuaciones para conseguir un mayor protección y en prevenir y evitar la incidencia negativa de las actividades humanas en el medio ambiente, ya que en muchos casos evitar la incidencia de riesgos es superior al posible remedio.

En efecto, el principio de integración del medio ambiente en las Políticas de la Comunidad Europea constituye actualmente uno de los fundamentos de la actuación comunitaria en el ámbito del medio ambiente; y contribuye expresamente a cumplir la filosofía y los objetivos del desarrollo sostenible.

Este principio comienza a tenerse en cuenta la Sentencia del Tribunal de Justicia de 7 de febrero de 1985 (Asunto relativo a la Asociación de Defensa de Quemadores de Aceites Usados) al afirmar el carácter prioritario de la protección ambiental. En un paso más, el Acta Única Europea mencionó este principio en la nueva Política Ambiental Comunitaria (al incluirlo en el art. 130 R-2 ${ }^{\circ}$, TCEE). Seguidamente, el Tratado original de la Unión Europea, al modificar esta Política en el TCE, enfatiza el principio. Posteriormente, el Quinto Programa Ambiental (1993-2000) destaca «...la imperiosa necesidad de tener en cuenta las consideraciones ecológicas a la hora de formular y aplicar las políticas económicas y sectoriales, en las decisiones de los poderes políticos, en la dirección y el desarrollo de los procesos de producción y en el comportamiento y elecciones personales»; mencionando, además, el principio de responsabilidad compartida. Finalmente, la revisión del Programa, llevada a cabo en 1998, insiste en el objetivo de alcanzar «la plena integración de la política de medio ambiente y otras políticas».

Con estos antecedentes, el Tratado de Amsterdam, al modificar el Tratado de la Comunidad Europea, incluye el nuevo art. 6 (suprimiendo la referencia del antiguo art. $\left.130 \mathrm{R}-2^{\circ}, \mathrm{TCE}\right)$, que señala:

«Las exigencias de la protección del medio ambiente deberán integrarse en la definición y en la realización de las políticas y acciones de la Comunidad a que se refiere el artículo 3, en particular con objeto de fomentar un desarrollo sostenible». 
De esta forma, el principio de integración ambiental deja de ser un principio de la Política Ambiental, para convertirse en un principio general de la actuación comunitaria, de cualesquiera de las políticas y acciones previstas en el artículo 3; dándole, pues, una amplitud significativa al colocarse al mismo nivel que los principios de competencias de atribución, de subsidiariedad y de proporcionalidad, recogidos en el art. 5-TCE. Así, este principio se convierte, quizás, en el más importante de todos, ya que, si el medio ambiente se ve afectado por otras políticas sectoriales (agricultura, transportes, energía, etc.), ese mismo medio ambiente exige una permanente y constante inspiración de todas esas mismas políticas que le afectan.

No obstante reafirmar la importancia del cambio operado en el Tratado $\mathrm{CE}$, debe señalarse que es un principio de actuación de la Comunidad Europea, cuya puesta en práctica depende de las Instituciones Comunitarias, las cuales gozan de una amplia discrecionalidad para ello.

A pesar de esto, la importancia del principio deriva, además de su consideración como un principio general de actuación de la Comunidad Europea, de las siguientes notas características: el art. 6-TCE mantiene su tendencia imperativa («deberán integrarse»); se aplica, de forma amplia y adecuada, tanto a la definición como a la realización de todas las acciones y políticas del art. 3-TCE; lo cual supone su carácter netamente preventivo, al exigirse su aplicación a la definición (incluyendo la planificación) y a la realización de las acciones y políticas; se aplica a todas las políticas comunitarias (letras a-n, art. 3-TCE), lo cual supone una amplitud destacable; en principio, se aplica a las políticas comunitarias, pero, dado que las mismas se llevan a cabo en y por los Estados Miembros, estos deben sentirse afectados por el principio; $\mathrm{y}$, finalmente, se vincula directamente a la consecución del desarrollo sostenible.

Por otra parte, la Política Ambiental Comunitaria, que nace claramente como política «curativa» en el Primer Programa Ambiental (1973-1976), no obstante, incluye en este mismo el objetivo, entre otros, de prevenir la contaminación y reconoce el principio preventivo en sus dos facetas: la sustantiva o material (la mejor política ambiental consiste más en prevenir la creación de contaminación y deterioro en su origen, que posteriormente combatir sus efectos) y la procedimental (los efectos sobre el medio ambiente deberían tenerse en cuenta en las fases lo más iniciales posibles de todos lo procesos técnicos de planificación y de toma de decisiones). No obstante, el Programa es totalmente sectorial en cuanto a los instrumentos recogidos.

El Segundo Programa Ambiental (1977-1981) inicia, tímidamente, un cambio sustancial en esta política, al poner especial atención en el principio preventivo (aunque sin abandonar el enfoque «a posteriori» de lucha contra la contaminación), que se reconoce y se convierte en una de las características de la Política Comunitaria. Recogiendo expresamente la «evaluación de las repercusiones en el medio ambiente», y previéndose estudios de la Comisión 
en este ámbito. De hecho, la propuesta de Directiva de Evaluación de Impacto Ambiental fue presentada por la Comisión en 1980. Además, el Programa incluyó otros instrumentos preventivos (cartografía ecológica; principio «quien contamina, paga»; gestión racional del espacio y de los recursos, etc.).

Será, sin embargo, el Tercer Programa ambiental (1982-1986) el que cambie totalmente la orientación de esta Política, hasta hacerla preventiva, siendo el principio uno de los ejes del mismo. Así, p. ej., la STS de 13 de diciembre de 1996 (AR. 9740) destaca esta evolución de los Programas.

El cambio es claro, pues, teniendo en cuenta las interrelaciones, a veces, muy estrechas que hay entre los diferentes recursos, es necesaria la concepción y aplicación de una estrategia global para la gestión de esos recursos. En el logro de este objetivo, el Programa integra tres principios: nivel adecuado de acción, prevención y restauración. Asimismo, dentro del principio preventivo se incluye la necesidad de reforzar la coherencia de la política comunitaria y de las políticas nacionales, y se destaca la importancia de las evaluaciones de impacto ambiental; siendo, así, aprobada la Directiva de Evaluación de Impacto Ambiental en 1985.

En lo que se refiere a los instrumentos de lucha contra la contaminación, el Programa señala que «por razones de orden práctico, la Comunidad y sus Estados miembros generalmente han procedido en esta materia mediante acciones específicas en cada uno de los aspectos del medio ambiente»; añadiendo que, al mismo tiempo «que proseguirá en este enfoque», «la Comisión concederá especial importancia a la coordinación de dichas acciones», y por ello «examinarán especialmente los medios para regular en su conjunto determinados vertidos que puedan afectar a varios medios, a fin de evitar cualquier transferencia de contaminación que resulte de medidas parciales». Si bien, este enfoque es el adecuado, el Programa no precisa más elementos; aunque sí se refiere a la necesidad de evitar las transferencias de contaminación producidas como consecuencia de medidas parciales.

Ya bajo la exigencia de las nuevas disposiciones del Acta Única Europea, se aprobó el Cuarto Programa Ambiental (1987-1992), que continúa la evolución de esta Política, confirmando el carácter preventivo. En cuanto a los problemas de la sectorialización del medio ambiente, el Programa señala que «ha predominado la tendencia a centrarse en los problemas de contaminación a medida que surgen en distintos medios: aire, agua, suelo»; reconociendo que, a pesar de algunos logros (como la Directiva EIA), recientes, «en general, se ha adoptado una visión sectorial que se refleja en la estructura de los propios servicios de la Comisión que se ocupan del medio ambiente».

Después de recordar la forma de intervención de la Comunidad en materia de aguas, aire y residuos, a través de enfoques sectoriales, el Programa estima que «una consecuencia inevitable del enfoque sectorial de la contaminación es que, dado que las normas se limitan a un área individual, los 
niveles puedan aumentar en otras áreas», siendo la Comisión de la opinión de que lo que necesita la Comunidad son «normas de medio ambiente cada vez más estrictas en todos los sectores»; concluyendo que el enfoque por sectores de los problemas de la contaminación no es necesariamente «la solución económicamente más rentable»; prefiriendo los denominados «enfoques multimedios». En cuanto a los controles basados en las sustancias, se menciona expresamente el enfoque integrado, que la Comisión pone en marcha a través de la regulación del amianto. Asimismo, el Programa prevé controles del origen de la contaminación, al ser necesario tener en cuenta la interacción entre tales orígenes de los contaminantes; si bien, a veces puede ser conveniente concentrar los controles en un único origen. Concluye la Comisión señalando que ningún enfoque es preferible a otros, dependiendo de cada caso concreto, y añadiendo que la Comunidad ha experimentado numerosos enfoques de protección ambiental como para «hacer conveniente una revisión global del asunto», con la finalidad de determinar si puede existir una base que proporcione orientaciones adecuadas sobre los enfoques futuros a adoptar por la legislación comunitaria; revisión que se llevará a cabo de forma coordinada con los Estados Miembros. Sin embargo, el Programa sigue utilizando los enfoques sectoriales.

El Quinto Programa Ambiental (1993-2000) da un paso más en esta misma dirección, al incluir entre sus prioridades la «lucha integrada contra la contaminación», con la finalidad de evitar (o reducir al máximo) las emisiones al aire, al agua y al suelo, para alcanzar un elevado grado de protección del medio ambiente en su totalidad, ya que contribuye considerablemente a avanzar hacia un equilibrio sostenible entre la actividad humana y el desarrollo socioeconómico, por un lado, y los recursos naturales, por otro. Este Programa da un salto cualitativo de gran importancia en este sentido, pues a partir del mismo las nuevas generaciones de normas incluirán un política ambiental no sectorializada, que no atienden a los problemas ambientales desde una perspectiva parcial, sino integrada y formulada como un conjunto coordinado. $\mathrm{Y}$ así durante la vigencia de este Programa se aprobará la Directiva de Control Integrado de la Contaminación, en 1996. La revisión del mismo, llevada a cabo por Decisión n ${ }^{\circ}$ 2179/98/CE, del Parlamento Europeo y del Consejo, de 24 de septiembre de 1998 (DOCE L 275, 10.10.1998), propone un marco que complemente el control integrado de la contaminación de instalaciones de menor tamaño.

\section{B) La Directiva 96/61/CE, del Consejo, de 24 de septiembre de 1996, relativa a la Prevención y al Control Integrados de la Contaminación}

Con estos antecedentes, el Consejo aprobó la Directiva 96/61/CE, de 24 de septiembre de 1996, relativa a la Prevención y al Control Integrados de 
la Contaminación (DOCE L 257, 10.10.1996); la cual será modificada posteriormente (Directiva 2003/35/CE, de 26 de mayo de 2003, DOUE L 156, 25.62003; Directiva 2003/87/CE, de 13 de octubre de 2003, DOUE L 275, 25.10.2003, y Reglamento (CE) $\mathrm{n}^{\circ} 1882 / 2003$, de 29 de septiembre de 2003, DOUE L 284, 31.10.2003).

El objeto de esta Directiva es la prevención y la reducción integradas de la contaminación procedente de las actividades incluidas en su ámbito de aplicación, con la finalidad de evitar o, cuando no sea posible, reducir las emisiones de esas actividades a la atmósfera, el agua y el suelo, incluyendo las medidas sobre residuos, siendo su objetivo final alcanzar su nivel elevado de protección del medio ambiente considerado en su conjunto.

Como características más sobresalientes de la Directiva destacamos:

- Utiliza el sistema clásico de intervención pública en materia ambiental, de carácter preventivo y muy usado, sectorialmente, en los distintos medios (aire, aguas y residuos): la autorización administrativa, en este caso, el permiso integrado. Este carácter integrado es, precisamente, muy novedoso en el ámbito jurídico,

- Su objetivo es claramente la prevención ambiental,

- Su enfoque integrado, al tratarse de controlar de manera conjunta, prácticamente, todas las contaminaciones que generan las industrias incluidas en su ámbito (así, aire, agua, suelo y los residuos); además, se integran las vibraciones, el calor y el ruido, además de las sustancias. En particular, este enfoque implica la prevención ambiental en origen (o en la fuente), es decir, evitando que la contaminación se llegue a producir, siguiendo lo establecido en los Tratados Europeos,

- En su ámbito se incluyen únicamente actividades industriales; no refiriéndose a las actividades agrarias ni al sector de los transportes,

- Es una Directiva Marco, pues se necesitan normas ulteriores para la fijación de los valores límite de todas las emisiones contaminantes. Sirve, pues, de marco a todas las normas relativas a todos los sectores ambientales implicados (y no como las anteriores que constituían un marco en un sólo sector).

La Directiva establece la obligación de los Estados miembros de garantizar que no puedan explotarse instalaciones nuevas sin un permiso integrado concedido conforme a la misma, y que constituye la parte esencial de esta norma.

El régimen jurídico del permiso integrado se inicia con la regulación del contenido de la solicitud del permiso (que es muy completo). El eje esencial del procedimiento es el enfoque integrado en la concesión de estos permisos. La finalidad del enfoque integrado, y que constituye la novedad del sis- 
tema, es sustituir las diferentes autorizaciones sectoriales por una, por el permiso integrado; destacándose, por ello, la importancia de la materia para la protección ambiental. No obstante, la Directiva no obliga a ello en ningún precepto, es más, en el concepto de «autoridad competente», incluye a «la autoridad, autoridades u organismos que, en virtud de la legislación de los Estados Miembros, sean responsables del cumplimiento de las tareas derivadas de la presente Directiva»; y parece pregonar el respeto, casi, al «status quo» actual, teniendo en cuenta que el Derecho Comunitario no altera la distribución interna de competencias (STC 80/1993, de 8 de marzo). Ante este verdadero problema, la Directiva estableció la obligación de los Estados miembros de tomar «las medidas necesarias para coordinar plenamente el procedimiento y las condiciones de autorización cuando en dicho procedimiento intervengan varias autoridades competentes».

Se prevé la información pública sobre las solicitudes, durante un período de tiempo adecuado, a fin de que se puedan formular alegaciones antes de que se tome la decisión; que se pone, también a disposición del público, y se prevén consultas al Estado miembro que pueda afectarle la instalación.

Posteriormente, se adoptará la resolución sobre el permiso integrado, que ha de ser por escrito, acompañada de condiciones que garanticen que la instalación cumplirá los requisitos de la Directiva; en caso contrario, se denegará; además, debe incluir las modalidades para la protección del aire, el agua y el suelo contempladas por la misma. Las condiciones del permiso, es decir, su contenido, constituyen el estatuto de protección del medio ambiente en función de la explotación de una instalación concreta y determinada; teniendo en cuenta que son posibles obligaciones particulares impuestas por los Estados miembros, para categorías específicas de instalaciones, garantizando el enfoque integrado y el nivel elevado de protección equivalente. Condiciones de los permisos que deben ser cumplidas por los titulares de las instalaciones industriales. La Directiva regula, obviamente el régimen de los cambios en las instalaciones y la revisión y actualización de los permisos integrados.

El segundo pilar central del sistema de protección de la Directiva se basa en la aplicación de las «mejores técnicas disponibles», definidas como la fase más eficaz y avanzada del desarrollo de las actividades y de sus modalidades de explotación, que demuestren la capacidad práctica de determinadas técnicas para constituir, en principio, la base de los valores límite de emisión destinadas a evitar o, cuando ello sea practicable, reducir en general las emisiones y el impacto en el conjunto del medio ambiente; entendiendo el concepto de «disponibles» como técnicas cuya aplicación sea en condiciones económicas y técnicamente viables, teniendo en cuenta los costes y beneficios, tanto si se producen en el Estado miembro como si no, y el concepto de «mejores» se vincula a las técnicas más eficaces para alcanzar un alto nivel de protección ambiental. Así, son, sin duda, una de las claves de la Directi- 
va al ser su utilización obligatoria, por ser el instrumento adecuado para la prevención de la contaminación. Además, los «valores límite» de las emisiones, que se deben especificar en el permiso integrado, se calculan sobre la base de las mejores técnicas disponibles.

La Directiva reconoce el acceso a la justicia, que obliga a los Estados Miembros a garantizar los recursos, administrativos o judiciales, en relación con aspectos regulados en la misma.

De acuerdo con lo establecido en la propia norma, la Comisión hizo público el «Informe sobre la aplicación de la Directiva relativa a la Prevención y Control Integrados de la Contaminación» [COM (2005) 540 final, Bruselas, 3.11.2005], que se centra en los años 2000 a 2002. Como resultados más destacables, el texto detecta retrasos en la transposición, planteamientos diversos en este proceso, un número limitado de concesión de permisos integrados, haciendo, pues, necesarios más avances para garantizar la aplicación completa de la misma antes de 2007; destacando ciertos problemas concretos y algunas opiniones de los Estados miembros.

\section{III) LA LEGISLACIÓN ESPAÑOLA SOBRE PREVENCIÓN AMBIENTAL Y CONTROL INTEGRADO DE LA CONTAMINACIÓN}

España no ha dispuesto hasta 2002 de un sistema integrado de autorizaciones de actividades industriales, para prevenir la contaminación y el deterioro ambientales. En nuestro país existía el mismo problema de sectorialización en la intervención pública para proteger el medio ambiente.

\section{A) La intervención administrativa en la industria: aspectos generales e históricos}

Las medidas de intervención administrativa en la industria han sido una constante histórica; si bien las mismas se han justificado por diversas razones, que han aparecido con el paso del tiempo: en una primera época, para eliminar los obstáculos y limitaciones a la libertad de empresa; posteriormente, para fomentar el desarrollo industrial, y en otras ocasiones para encauzar la incidencia industrial en otros bienes y derechos que también deben ser protegidos por la Administración.

$\mathrm{Si}$, con carácter general, se pueden realizar las afirmaciones anteriores, inmediatamente hay que señalar que tal intervención, a pesar de ser constante, ha sido muy desigual, dependiendo, en el tiempo, de consideraciones políticas y económicas, y ha utilizado, también de forma desigual, las diferentes 
técnicas tradicionales de actuación de las Administraciones Públicas (medidas de intervención y policía, fomento, actividad de prestación, gestión económica, etc.). Ello es debido a la pluralidad de fines a que responden las intervenciones, no fácilmente deslindadas debido a la compatibilidad existente entre ellos; teniendo en cuenta, además, la plasmación de los fines y las intervenciones administrativas en diferentes normas jurídicas, cuestión que se ha acrecentado con el aumento de la complejidad socioeconómica, y de la propia actividad industrial.

Las actividades industriales provocaron una primera regulación jurídica vinculada a las relaciones de vecindad, y a los derechos de propiedad (así, arts. 590 y 1908 del Código Civil), y, asimismo, una primera intervención administrativa, vinculada a las relaciones de vecindad también, relacionados con la tranquilidad de los ciudadanos. Posteriormente, y sin dejar de tener aplicación lo anterior, la intervención administrativa se justificará por razones sanitarias, en particular debido a la amplia y aguda incidencia negativa en la salud de las primeras actividades industriales contemporáneas.

Más adelante, el importante desarrollo económico e industrial posterior a la II Guerra Mundial provocó beneficios tangibles, pero también efectos negativos muy claros, como el deterioro y la contaminación ambiental generalizada. Tal situación convirtió la protección ambiental en una función pública a partir de los años 70 (arts. 9 y 66 de la Constitución Portuguesa o art. 45 de nuestra Constitución). En este contexto de necesaria compatibilidad entre el desarrollo económico y el medio ambiente (STC 64/1982, de 4 de noviembre), se han revalorizado las técnicas de carácter preventivo, con la forma de permisos, licencias o autorizaciones, al convertirse ese principio preventivo en uno de los ejes estructurales de toda política ambiental (así recogido en los Tratados Europeos y en otros textos, como hemos visto).

Por ello, teniendo los Poderes Públicos (art. $45-2^{\circ}$ de la Constitución Española), como función, velar «por la utilización racional de todos los recursos naturales, con el fin de proteger y mejorar la calidad de vida y defender y restaurar el medio ambiente» [...], uno de los instrumentos más utilizados en la materia son las autorizaciones o licencias administrativas, ya que permiten a las Administraciones Públicas contrastar las actividades concretas con el ordenamiento jurídico, en general, antes de permitirlas; en este caso, permiten contrastar la incidencia de la actividad en el medio ambiente, con el fin de autorizarlas o no. La Ley 21/1992, de 16 de julio, de Industria (BOE del 23) hace referencia, en sus arts. 2 y 4 , con carácter general a este proceso.

El inicio del proceso industrial hizo visible la insuficiencia de los planteamientos civiles señalados, vinculados a las relaciones de vecindad y al derecho de propiedad, en la resolución de los problemas y conflictos generados por la incipiente actividad industrial; obligando a la intervención de los Poderes Públicos, y, en particular, de la Administración. 
Así, las mismas Cortes de Cádiz reconocen la libertad de establecimiento de «fábricas o artefactos» sin necesidad de permiso ni licencia alguna si se sujetaban a las reglas de la policía de salubridad de los pueblos (Decreto de 8 de junio de 1813).

A lo largo de los años siguientes se producen intervenciones diversas en sentido parecido, si bien el problema se plantea claramente en la Real Orden de 8 de enero de 1884 (Gaceta del 22), sobre el establecimiento de nuevas industrias e inventos y la prohibición dentro de las poblaciones de las insalubres y peligrosas.

Primando las relaciones de vecindad, seguidamente, el art. 590 del Código Civil, de 1889, establece la prohibición de construir instalaciones que por sí mismas o por sus productos sean peligrosas o nocivas, cerca de pared ajena o medianera «sin guardar las distancias prescritas por los Reglamentos y usos del lugar y sin ejecutar las obras de resguardo necesarias, con sujeción, en el modo a las condiciones que los mismos Reglamentos prescriban». Por su parte, el artículo 1908 del mismo Código Civil establece la responsabilidad por los daños derivados de las actividades que incumplan el precepto anterior.

Entre las normas de carácter general en esta materia, es destacable la Instrucción General de Sanidad Pública, aprobada por Real Decreto de 12 de enero de 1904 (Gaceta de los días 22 y 23). Siguiendo las pautas de la época, la Instrucción incluye, en el ámbito de la «higiene municipal» (art. 109), «la supresión, corrección o inspección de establecimientos o industrias nocivas a la salud pública», y, por ello, obliga a los Ayuntamientos a que aprobasen un reglamento de higiene, sujetándose a las prescripciones de la Instrucción. Por su parte, el art. 143 recoge la regla general de que ningún taller o fábrica «que produzcan gases o emanaciones insalubres, así como los que viertan aguas o residuos que impurifiquen las corrientes de aguas públicas o destinadas al servicio público», pudiera abrirse sin que preceda la oportuna licencia. Finalmente, su art. 144 prevé una intervención provincial o estatal para normalizar y armonizar diversas cuestiones relativas a estos establecimientos (condiciones, distancias, etc.).

Posteriormente, por Real Orden de 12 de octubre de 1910 (Gaceta del 9 de diciembre), se aprobaron «las bases generales a que han de ajustarse los Reglamentos municipales de Higiene», previstos en la Instrucción General, entre cuyas prescripciones destacamos la prohibición en el interior de las poblaciones de toda chimenea de fábrica o establecimiento análogo «que no consuma de una manera completa sus humos», la prohibición de vaquerías en el interior de poblaciones, «como no sea en edificio construido a propósito» y obligando a los establecimientos insalubres, peligrosos e incómodos a cumplir todas las normas en la materia destacando, respecto de éstos, la obligación de «purificar» las aguas residuales antes de verterlas a aguas públicas; cuestiones de plena actualidad, a pesar del tiempo transcurrido. 
El Reglamento de Obras, Servicios y Bienes Municipales, aprobado por Real Decreto de 14 de julio de 1924 (Gaceta del 16), en la misma línea, parte de la exigencia de previa licencia municipal para las obras. En cuanto a las fábricas y establecimientos industriales que fueran insalubres, incómodos o peligrosos, el Reglamento remite también a las Ordenanzas municipales, haciendo expresa referencia a la separación respecto a «lugares destinados a habitación» y a que su funcionamiento no pueda implicar perjuicio ni peligro; se regula la obligación de la previa visita de inspección pública a su apertura, como medio de control y se prevé la elaboración de un nomenclátor sobre tales industrias, a tener en cuenta por las Ordenanzas locales.

Insistiendo en los planteamientos ya conocidos, el Reglamento de Sanidad Municipal aprobado por Real Decreto-Ley de 9 de febrero de 1925 (Gaceta del 17), obliga a que las Ordenanzas municipales contengan disposiciones sobre policía sanitaria de mercados, mataderos, tiendas de comestibles, establecimientos públicos y fábricas e industrias insalubres, entre otras actividades. Por su parte, también ratifica la competencia de los Ayuntamientos para conceder las licencias de instalación y apertura de establecimientos industriales, previo dictamen de la Junta Municipal de Sanidad, y reitera la prohibición de ubicación de estas industrias si no cumplen la distancia de separación adecuada y las condiciones para hacerlas inocuas. Finalmente, obliga a los Municipios con más de 15.000 habitantes a poner en marcha servicios de «higiene industrial, vigilancia de las industrias nocivas y saneamiento o clausura de las incorregibles», así como de los establecimientos para espectáculos públicos, mataderos o similares.

Como hemos visto, el Reglamento de Obras, Servicios y Bienes Municipales, de 1924, obligaba a la elaboración de Nomenclátor de Industrias Incómodas; excediéndose, claramente, de tal mandato, la Real Orden de 17 de noviembre de 1925 aprobó el Reglamento de Establecimientos clasificados Incómodos, Insalubres o Peligrosos (Gaceta del 27), iniciando una línea de intervención pública específicamente dirigida a las actividades clasificadas, distinta a la legislación sanitaria, habitual en esa materia hasta esta época.

La separación definitiva de las dos normativas en esta materia (una sanitaria y otra sobre actividades clasificadas) se manifiesta claramente en la Ley de Bases de Sanidad Nacional, de 1944, al omitir toda referencia expresa a estas actividades e industrias, y se confirma definitivamente con la aprobación del Reglamento de Actividades Molestas, Insalubres, Nocivas y Peligrosas, por Decreto 2414/1961, de 30 de noviembre (BOE de 7 de diciembre de 1961 y 7 de marzo de 1962), y de su Instrucción Complementaria, por Orden Ministerial de 15 de marzo de 1963 (BOE del 2 de abril).

Justificado en la necesidad de dar respuestas jurídicas a la consolidación de la sociedad industrial y al desarrollo e impacto de los procesos industriales, el RAMINP prevé dos técnicas protectoras fundamentales (que en su 
esencia provienen del Reglamento de 1925): el «alejamiento» de las actividades clasificadas y la imposición de medidas correctoras.

En efecto, el emplazamiento de las industrias, insalubres y peligrosas queda prohibido a una distancia inferior a 2.000 metros del núcleo más próximo de población agrupada (artículo 4-RAMINP) (STS 4.10.1991, AR.7848). Esta previsión, que constituye uno de los ejes del Reglamento, no ha sido muy efectiva, al ser superada por la generalización de los instrumentos de planificación urbanística para enmarcar la ubicación de las actividades industriales, por la no prohibición de acercamiento de las viviendas a las actividades industriales y porque se prevén excepciones al alejamiento (artículos 20RAMINP y 11 de la Instrucción).

La segunda de las técnicas previstas (la previsión de un conjunto de medidas correctoras, tanto en el Reglamento como en el artículo 10 de la Instrucción) tampoco ha sido muy efectiva, pues su eficacia se agota en el momento inicial de la instalación, no estando previstas modificaciones posteriores en las industrias ya instaladas. Cuestión que sí prevé, parcialmente, el art. 9-3º de la Instrucción, al referirse a la variación de la calificación de la industria o actividad, y, también, una numerosa jurisprudencia del Tribunal Supremo.

Por otro lado, el Reglamento somete a previa licencia la apertura de las actividades industriales clasificadas en el mismo, con el fin de controlar su adecuación a las medidas previstas, disciplinando adecuadamente el funcionamiento de las mismas (así, en general, el procedimiento se analiza en la STS 1.10.1997, AR. 7032).

Del procedimiento de concesión de las licencias, es destacable la pérdida de la competencia municipal, en favor, en la actualidad, de los órganos competentes en la materia de las Comunidades Autónomas, al preverse (después del desarrollo del proceso de descentralización territorial previsto en la Constitución Española) la obligación de los Ayuntamientos de otorgar o denegar la licencia solicitada «en consonancia» con el acuerdo de estos órganos. No obstante, la intervención municipal sigue considerándose muy im-

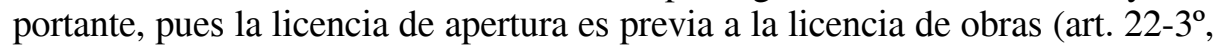
Reglamento de Servicios de las Corporaciones Locales, de 1955), siendo ésta plenamente municipal. Además, esta prioridad de la licencia de actividad clasificada respecto a la de obras, remarca el carácter cualitativo y horizontal de la primera, primando las consideraciones ambientales, respecto a las urbanísticas y de uso del suelo.

El sistema del RAMINP incluía una característica muy positiva y destacable para su tiempo, como era su carácter global, integrador y amplio, muy adecuada a las concepciones del medio ambiente, y de su protección, que pronto se ha eliminado, a través de la proliferación de normativas sectoriales, que ha terminado por atribuir al Reglamento casi la consideración de «norma residual», aplicable cuando no existe otra más específica. 


\section{B) La incidencia de la Constitución Española de 1978}

Un breve repaso a las listas de materias, a efectos de su distribución entre el Estado y las Comunidades Autónomas, de los arts. 148 y 149 de la Constitución, confirma que las actividades clasificadas no se mencionan; lo que nos lleva a la conclusión de la necesidad de su encuadramiento en alguna de las mencionadas en dichos preceptos; conclusión que se confirma al no mencionarse tampoco en las listas de competencias de las Comunidades Autónomas, previstas en sus Estatutos (salvo en el Estatuto de las Illes Balears, cuya mención va unida a la materia ambiental).

De los antecedentes normativos analizados, podemos concluir que la materia «actividades clasificadas» se debe incluir entre las competencias sobre «sanidad»y «medio ambiente», lo cual es coherente con los principios constitucionales y con varias sentencias del Tribunal Constitucional, al admitir que una misma actividad pueda ser subsumible en diversas competencias en función de su fin material. No obstante, el análisis de la normativa posterior a la Constitución nos permite señalar que la materia tiende, hoy, a aproximarse más hacia la competencia ambiental, aunque sigue presente la materia sanitaria (así, STS 4.10.1991, AR. 7848).

Respecto a ambas, la Constitución reserva al Estado la «legislación básica» (art. 149-1 $1^{\circ}, 23$, para el medio ambiente) o las «bases» (art. 149-1 ${ }^{\circ}, 16$, en sanidad), siendo posible el desarrollo de la normativa básica por las Comunidades Autónomas; si bien, en caso del medio ambiente, las Comunidades Autónomas pueden dictar «normas adicionales de protección».

Este sistema de distribución de competencias se ha generalizado para todas las Comunidades Autónomas, a través de la Ley Orgánica 9/1992, de 23 de diciembre, de Transferencias de Competencias (BOE del 24) y de la reforma de los Estatutos de algunas Comunidades Autónomas, llevada a cabo en 1994 (cuyas Leyes Orgánicas de modificación de publicaron en el BOE de 25 de marzo de 1994). En base a este esquema, varias Comunidades Autónomas promulgaron Leyes específicas en materia de actividades clasificadas, todas inclinándose hacia la fundamentación ambiental (p. ej., Comunidad Valenciana, Navarra, Madrid, Castilla y León, Galicia, Murcia o Andalucía).

Por último, se debe tener en cuenta, como es sabido, la intervención de la Administración Local en esta materia, derivada del reconocimiento constitucional de su autonomía y de las previsiones de la Ley de Bases de Régimen Local de 1985 (art. 147 de la Constitución y arts. 25, 26 y 28 de la Ley de Bases de Régimen Local).

De acuerdo con este esquema competencial, la determinación de «lo básico» corresponde al Estado mediante una norma con rango de Ley (aunque el Tribunal Constitucional, a veces, ha admitido excepcionalmente otro 
tipo de normas). Siendo esta la solución que parecía derivarse del artículo 4 de la Ley 21/1992, de 16 de julio, de Industria (BOE del 23), al requerir autorización administrativa previa para la instalación, ampliación y traslado de industrias «cuando así lo establezca una ley por razones de interés público».

No obstante, posteriormente, y debido a los debates producidos y al nuevo modelo de intervención administrativa en materia de medio ambiente, de carácter preventivo e integrador, la Administración General del Estado se inclinará por elaborar una nueva Ley en la materia, que se aleja del modelo anterior (el del RAMINP, actualizándolo), para poner en marcha un sistema de autorizaciones ambientales integradas, de acuerdo con la normativa europea.

\section{C) La Ley de Prevención y Control Integrados de la Contaminación de 2002}

Con la finalidad de cumplir con la Directiva de 1996, se elaboró y aprobó la Ley 16/2002, de 1 de julio, de Prevención y Control Integrados de la Contaminación (BOE del 2), que tiene por objeto establecer un sistema de prevención y control integrados de la contaminación, con la finalidad de alcanzar una elevada protección del medio ambiente, para evitar y, cuando no sea posible, reducir y controlar la contaminación de la atmósfera, el agua y el suelo.

La Ley, que sigue de cerca lo establecido en la Directiva de 1996, asume la nueva filosofía de la prevención y el control integrado de los procesos de contaminación, como pilar esencial de la protección ambiental, al introducir un nuevo sistema de intervención administrativa en la materia.

En efecto, el sistema de protección ambiental establecido en la Ley, con el carácter de legislación básica a efectos constitucionales, se articula en la exigencia de la nueva autorización ambiental integrada (el permiso integrado europeo) y en la utilización de las mejores técnicas disponibles, respecto a las instalaciones industriales incluidas en su ámbito de aplicación.

En cuanto a la autorización ambiental integrada, se define como la resolución del órgano competente de la Comunidad Autónoma en que se ubique la instalación (prevista en el Anexo I de la Ley), por la que se permite, a efectos de la protección ambiental y de la salud de las personas, explotar la misma bajo determinadas condiciones; sometiendo a la concesión de dicha autorización la construcción, montaje, explotación o traslado, así como la modificación, de las instalaciones mencionadas; con previsión expresa de los principios de cooperación y de coordinación entre las Administraciones Públicas en la tramitación y concesión de las mismas (estableciéndose, así, para 
ello un sistema de prevención y control integrado de la contaminación, que integre en un solo acto de intervención administrativa todas las autorizaciones ambientales existentes, la previsión expresa de la precedencia de la nueva autorización ambiental respecto a las restantes autorizaciones sustantivas o licencias y previendo que las Comunidades Autónomas deben integrar los procedimientos de concesión de estas autorizaciones con las evaluaciones de impacto ambiental, los relativos a accidentes graves y otros).

Este carácter integrador, y preventivo, de las nuevas autorizaciones ambientales integradas también se hace visible en el procedimiento de concesión, que se inicia con la presentación de la solicitud ante el órgano competente de la Comunidad Autónoma correspondiente y que prevé la emisión de informes de los Ayuntamientos afectados (de carácter urbanístico y sobre cuestiones de su competencia), de otros órganos competentes, del Organismo de Cuenca del Ministerio de Medio Ambiente (con el carácter de preceptivo y vinculante, de acuerdo con las competencias en materia de aguas) y los trámites habituales de información pública y audiencia a los interesados; procediéndose a su resolución (con silencio administrativo negativo, en su caso); estableciéndose su notificación a los interesados y su publicación, los recursos posibles, la modificación y renovación de la misma, así como la previsión de los efectos transfronterizos. Siguiendo el régimen de la Directiva, la Ley regula el contenido de las autorizaciones ambientales integradas, también de forma muy completa.

Como en el sistema de la Directiva, se prevé en la Ley la utilización de las mejores técnicas disponibles por las instalaciones afectadas, y en la determinación de los valores límite de emisión.

La Ley finaliza con la regulación del acceso a la información, del sistema de control e inspección, del régimen sancionador y de las medidas cautelares posibles, con previsión de la reposición del daño causado, en su caso.

\section{IV) LAS COMPETENCIAS Y LA LEGISLACIÓN DE LA COMUNIDAD DE CASTILLA Y LEÓN SOBRE PREVENCIÓN Y CONTROL INTEGRADO DE LA CONTAMINACIÓN}

\section{A) Las competencias de la Comunidad de Castilla y León sobre medio ambiente}

El Estatuto de Autonomía de Castilla y León, aprobado originalmente por Ley Orgánica 4/1983, de 25 de febrero (BOE 2 de marzo), de acuerdo con el art. 148-CE, reflejó normativamente el sistema competencial señalado. Así, el art. 25-EACYL incluye la materia «protección del medio ambiente, del 
entorno natural y del paisaje» entre las competencias ejecutivas o de gestión de la Comunidad. Lo cual implicaba, como sabemos, que, en Castilla y León, se aplicaba toda la normativa estatal en la materia, siendo posible únicamente dictar reglamentos de organización, y no reglamentos sustantivos. No obstante, hay que tener en cuenta que entre las competencias exclusivas (art. 26-EACYL) y entre las de desarrollo normativo (art. 27-EACYL), hay materias en relación estrecha con la protección ambiental.

La Ley Orgánica 9/1992, de 23 de diciembre (BOE del 24), amplió considerablemente las competencias y el margen de actuación de la Comunidad de Castilla y León.

Posteriormente, la Ley Orgánica 11/1994, de 24 de marzo (BOE del 25), modificó el Estatuto de Autonomía original, añadiendo, en el art. 27, como competencias de desarrollo normativo de la legislación básica del Estado (incluyendo la potestad legislativa), la materia de «normas adicionales de protección del medio ambiente»; correspondiendo, también a la Comunidad Autónoma la potestad reglamentaria, la gestión y la función ejecutiva, incluyendo la inspección. Además, en esta materia, subsiste, en el art. 28-EACYL, la referencia a las competencias de ejecución de la legislación básica del Estado. Por último, en relación con las materias conexas, la reforma del EACYL amplía, también, las competencias autonómicas.

Finalmente, por ahora, la Ley Orgánica 4/1999, de 8 de enero (BOE del 9) modifica, por segunda vez, el Estatuto Castellano y Leonés; introduciendo escasas novedades en materia ambiental, aunque alguna sea significativa. Así, se añade un nuevo art. 4-EACYL sobre «valores esenciales» de la Comunidad Autónoma; incluyendo «el patrimonio histórico, artístico y natural», declarándose que «serán objeto de especial protección y apoyo». Por su parte, el anterior art. 27 pasa a ser el art. 34-EACYL, sobre competencias de desarrollo normativo y ejecución; correspondiéndole a la Comunidad de Castilla y León, en el marco de la legislación básica y en los términos que establezca, «el desarrollo legislativo y la ejecución de la legislación del Estado en las siguientes materias: .../...5 $5^{\text {a }}$. Protección del medio ambiente y de los ecosistemas, sin perjuicio de las facultades de la Comunidad Autónoma para establecer normas adicionales de protección en los términos del artículo 149.1.23 $3^{a}$ de la Constitución». Correspondiéndole, asimismo, a la Comunidad Autónoma la potestad reglamentaria, la gestión y la función ejecutiva, incluida la inspección.

Con una redacción más depurada que en la reforma de 1994, se establecen claramente las competencias de Castilla y León, suprimiéndose también la referencia a las competencias de ejecución en materia ambiental que subsistían, al quedar englobadas en la redacción del nuevo art. 34-5, EACYL citado. 


\section{B) El primer sistema preventivo de intervención ambiental en la Comunidad: La Ley de Actividades Clasificadas de 1993 y sus normas de desarrollo}

El Programa de la Consejería de Medio Ambiente y Ordenación del Territorio para la Legislatura 1991-1995, presentado en las Cortes de Castilla y León, en el mes de octubre de 1991, incluía la elaboración del Proyecto de Ley de Actividades Clasificadas.

Texto que, una vez debatido y aprobado por las Cortes de Castilla y León, se convertiría en la Ley 5/1993, de 21 de octubre, de Actividades Clasificadas (BOCYL del 29) [LAC], modificada por Ley 2/1996, de 18 de junio (BOCYL del 24), estando ambas derogadas en la actualidad, y desarrollada mediante Decreto 159/1994, de 14 de julio, que aprueba el Reglamento de Aplicación (BOCYL del 20), a su vez modificado mediante Decreto 66/1998, de 26 de marzo (BOCYL del 30).

La Exposición de Motivos de la Ley justificaba su publicación, en primer lugar, en la necesidad de una norma con rango de Ley para actuar eficazmente las potestades públicas de inspección y disciplinarias; en segundo lugar, en la posibilidad de realizar delegaciones de competencias en la materia, de acuerdo con la Ley 6/1986, de 6 de junio, de Relaciones entre la Comunidad de Castilla y León y las Entidades Locales (BOCYL del 11), y, por último, en las competencias de la Comunidad en materia de sanidad e higiene y en materia de ordenación del territorio, urbanismo y vivienda. No obstante, la referencia a las competencias ambientales de la Comunidad Autónoma se debía de haber mencionado, ya que la Ley Orgánica de Transferencias había procedido a ello en diciembre de 1992, según hemos visto anteriormente.

El objetivo de la Ley (art. 1) es regular el régimen de autorización y funcionamiento de las actividades clasificadas por la Legislación estatal como molestas, insalubres, nocivas y peligrosas, en el territorio de Castilla y León. No obstante, el párrafo $2^{\circ}$ de este artículo flexibiliza y amplía el objeto de la misma al someter a su régimen jurídico «cualquier actividad o instalación susceptibles de ocasionar molestias, alterar las condiciones de salubridad, causar daños al medio ambiente o producir riesgo para las personas o bienes».

Las actividades sometidas a la Ley se incluían (art. 2) en una larga lista no limitativa, de carácter general y ambigua en sus conceptos [la lista incluye 16 apartados, que van desde las actividades o instalaciones nucleares y radiactivas, extractivas o en materia energética hasta mataderos, comercio de alimentación, hostelería o garajes; siendo destacables, por su generalidad y ambigüedad, los apartados «h) Industrias en general, incluso talleres», «k) Comercio de alimentación en general», «l) Servicios en general» o, finalmente, «ll) Hostelería»]; ambigüedad y amplitud muy positivas desde el punto de vista protector, al permitir incluir un gran número de actividades e instalaciones, 
pero no tan positivo desde el punto de vista del titular de la actividad, en relación a su seguridad jurídica, sobre si se incluye o no en el ámbito de la Ley, respecto a su cumplimiento. Esta cuestión se hubiera solucionado mejor con la remisión a un nomenclátor de actividades propio o al recogido en el RAMINP estatal; remisión, esta última, que, a nuestro juicio, sí era posible por la referencia a la «legislación estatal» que incluye el propio art. 1LAC. Además, por otra parte, la Junta de Castilla y León podía declarar exentas algunas actividades o incluir otras no previstas; cuestión que desarrolla el art. 5 del Reglamento de Aplicación, al declarar exentas de calificación e informe las actividades del Anexo adjunto (si bien, se les aplica el resto de la Ley, las normas sobre ruidos y vibraciones y las sectoriales), justificándose, según la Exposición de Motivos del Reglamento, en que son actividades que no inciden negativamente sobre el medio ambiente, en que se desea armonizar la tutela efectiva del medio ambiente y la adecuación de la actividad administrativa a los principios de proporcionalidad, agilidad y rapidez, y en que se desea garantizar «una aplicación máxima» del derecho de libertad de empresa. El Reglamento, por otra parte, establece la obligación de los Ayuntamientos de mantener un registro de estas actividades (art. 2).

A la vista de estas justificaciones, y teniendo en cuenta la lista del Anexo (13 actividades o instalaciones), cabe hacer las siguientes consideraciones:

- en cuanto a la poca incidencia en el medio ambiente, hay que señalar que la relativa a «redes de distribución y transporte de energía eléctrica, gas, vapor y agua» (letra m), sí puede tener incidencia, así como los diversos talleres recogidos en las letras a, b, c y d, y las instalaciones de almacenamiento de combustibles líquidos o gaseosos para usos no industriales ni comerciales (letra h);

- algunas actividades (letras e y f, sobre «corrales domésticos» e «instalaciones para cría o guarda de perros»), aunque sean pequeñas, son molestas, y no deberían, por ello, haberse declarado exentas; si bien, y es verdad, la Comunidad de Castilla y León es una región con muchos Municipios pequeños y dedicados a la agricultura y ganadería (en los cuales podría tener sentido la exención), no se ha de olvidar que desde el RAMINP de 1961 (e incluso antes) se han prohibido las «vaquerías, establos, cuadras y corrales de ganado y aves dentro del núcleo urbano de las localidades de más de 10.000 habitantes y que no sean esencialmente agrícolas o ganaderas»; prohibición no expresamente recogida en la Ley, pero que entendemos vigente por la remisión del art. 1-LAC a la Legislación estatal señalada (véase la STS de 8 de octubre de 1997, AR. 7044, sobre ese problema).

- la «aplicación máxima» del derecho de libertad de empresa, no puede significar la no existencia de límites, ya que se prevén en la propia Constitución Española (art. 38); entre los que se encuentran los ambientales y los relativos a la protección de la salud, a ponderar por el legis- 
EL RÉGIMEN JURÍDICO DE LA PREVENCIÓN AMBIENTAL EN LA COMUNIDAD DE CASTILLA Y LEÓN

lador. Así se señala claramente en la citada STS. 8 de octubre de 1997 (Ar. 7044).

El sistema protector de la Ley de Actividades Clasificadas giraba en torno al régimen de obtención de las licencias correspondientes y a los sistemas de inspección y sancionador administrativos.

Dentro de la clásica actividad de policía administrativa, la Ley de Actividades Clasificadas distinguía dos tipos de licencias, ya conocidas: la Licencia de Actividad (arts. 3 a 12) y la Licencia de Apertura (arts. 16 a 19).

La Licencia de Actividad es la autorización administrativa previa y necesaria, a la instalación, ampliación o reforma de una actividad clasificada. Se solicita, por el interesado, al Ayuntamiento en cuyo territorio se pretenda ubicar la actividad, aportando la documentación exigida por los arts. 4-LAC y 3-Reglamento de Aplicación, entre cuyo contenido es destacable la exigencia de «una memoria descriptiva en la que se detallen sus características; la incidencia sobre la salubridad y el medio ambiente y los riesgos potenciales para personas o bienes, así como las medidas correctoras propuestas». Esta licencia establece las directrices sobre las instalaciones y obras.

La misma se concede o deniega por el Alcalde, mediante un procedimiento, en el que son destacables los trámites de información pública (durante 15 días), con expresa notificación a los vecinos inmediatos al lugar del emplazamiento propuesto y a aquellos que por su proximidad a éste pudieran verse afectados, y la participación de las nuevas Comisiones Provinciales de Actividades Clasificadas (cuyo régimen jurídico regulan los arts. 6 a 11 del Reglamento de Aplicación; en sustitución de las anteriores Comisiones Provinciales de Saneamiento), resaltando, sobre todo, el carácter vinculante de sus informes, si son denegatorios de la licencia o implican la imposición de medidas correctoras adicionales (art. 5-3 ${ }^{\circ}$, LAC; precepto que aparentemente parece que tiene ciertos problemas de constitucionalidad por poder implicar un control jerárquico sobre las Corporaciones Locales, contrario a la autonomía local que reconoce la propia Constitución, siempre que los efectos de la actividad no trasciendan del término municipal o cuando el interés general o autonómico no prevalezca sobre el municipal; no obstante, la STS de 24 de octubre de 1997, AR. 7543, citando algunas más, admite sin problemas tales informes, y sus efectos); por lo cual, la LAC prevé la audiencia al interesado, previa a la decisión definitiva de la Comisión, y la devolución del expediente al Alcalde para que resuelva (art. 5-5 ). Asimismo, es resaltable la previsión del otorgamiento de esta licencia de actividad por silencio administrativo positivo, por el transcurso de cuatro meses, a contar desde el día siguiente a su solicitud; no permitiéndose la adquisición de facultades en contra de la propia Ley, o sus normas de desarrollo, y de la legislación sectorial aplicable, por silencio administrativo. No obstante, esta institución no se aplica si ha de intervenir la Comisión Regional de Actividades Clasificadas (art. 8). Por último, el art. 11-LAC establece, con buen criterio, la revisión de la licen- 
cia de actividad en base a la legislación ambiental vigente, y se prevé su adaptación al progreso científico y técnico.

La Licencia de Apertura debe obtenerse del Alcalde correspondiente, con carácter previo al inicio de una actividad clasificada. Es pues, la autorización administrativa de la puesta en marcha de la actividad (arts. 16-LAC y 4-Reglamento de Aplicación). Su finalidad es comprobar que las prescripciones de la licencia de actividad se cumplen, así como las medidas requeridas en la misma. Para ello, se establece la necesidad de un certificado, firmado por el técnico titulado competente, relativo a que la instalación se ajusta al proyecto aprobado y, en su caso, a las medidas correctoras impuestas, detallándose las mediciones y comprobaciones efectuadas. Realizadas las correspondientes comprobaciones, el Alcalde resolverá razonadamente sobre la concesión o denegación de la licencia de apertura. Al igual que en el caso de la licencia de actividad, se prevé la concesión de la licencia de apertura por silencio administrativo positivo, por el paso de un mes, desde su solicitud (art. 18-LAC).

La posible regularización de actividades sin licencia se prevé en el art. 26LAC, si la actividad puede autorizarse cumpliendo determinados requisitos, aunque también se establece la posible clausura de las instalaciones, si no pudieran ser regularizadas.

El art. 19-LAC establecía una de las medidas más importantes para la protección ambiental del texto legal, que era el establecimiento de prioridades entre licencias y otro tipo de autorizaciones. En efecto, se prescribe que las Entidades Locales «no podrán conceder» licencias de obras para estas actividades sin tenerse otorgada la licencia de actividad, y que la licencia de apertura «será previa» a las autorizaciones de enganche o ampliación de suministro de energía eléctrica, de utilización de combustibles líquidos o gaseosos, de abastecimiento de agua potable y demás autorizaciones preceptivas. De esta forma, la Ley reconoce claramente el carácter horizontal o transversal de la actividad ambiental respecto a las actividades sectoriales; convirtiéndose, así, ambas licencias en auténticos instrumentos preventivos en materia ambiental. Sin embargo, y a pesar de la claridad y rotundidad de lo establecido por el artículo señalado, el Reglamento de aplicación (art. 4$3^{\circ}$ ) admite la concesión de «autorizaciones provisionales» de enganche o ampliación a los servicios mencionados (energía eléctrica, combustibles, agua y otros), en contradicción con lo prescrito en la Ley, que no las prevé.

Tales autorizaciones provisionales, no obstante, se regulan en el Reglamento con importantes limitaciones: temporales, pues únicamente se permiten por el tiempo necesario hasta la obtención o derogación de la licencia de apertura; materiales, pues no pueden producir molestias, alteraciones de la salubridad, daños ambientales o riesgos para personas y bienes; y finalistas, pues tales autorizaciones provisionales se conceden para realizar las pruebas necesarias para ejecutar el proyecto y las medidas correctoras previstas en la licencia de actividad. No cabe duda que tales limitaciones (que deben inter- 
pretarse restrictivamente, al ser disposiciones que excepcionan el régimen general: la prioridad de las licencias de actividades clasificadas) enmarcan perfectamente las autorizaciones provisionales, con lo que se debería impedir su generalización; pues, de otra forma, los objetivos finales de la Ley podrían verse afectados negativamente.

El sistema protector del medio ambiente de la Ley de Actividades Clasificadas continuaba con la regulación del régimen de inspección y funcionamiento de tales actividades e instalaciones.

Las competencias de inspección de las actividades clasificadas corresponden a los Ayuntamientos en cuyo término estén ubicadas (art. 20-1 ${ }^{\circ}$, LAC). Además, el mismo precepto asignaba la alta inspección en la materia a la entonces denominada Consejería de Medio Ambiente y Ordenación del Territorio; si bien, salvaba la posible intervención de otros órganos (p. ej., de las Consejerías competentes en materia de sanidad o de consumo).

El art. 21-LAC establecía, con muy buen criterio, que el personal que llevara a cabo, oficialmente, las labores de inspección, gozaría de la consideración de «agente de la autoridad» a efectos penales; siendo posible que tales inspectores puedan acceder, previa identificación, y sin previo aviso, a las instalaciones donde se desarrollen las actividades clasificadas, y estando, también, previsto el deber de colaboración con los mismos de los titulares de las actividades clasificadas.

Advertidas deficiencias en el funcionamiento de las instalaciones (por el Ayuntamiento y la entonces Consejería de Medio Ambiente y Ordenación del Territorio, pero también por los ciudadanos, mediante denuncias, e incluso por propio titular, como derivación del deber de colaboración señalado), el Alcalde, o en su defecto, si no actúa, la Consejería citada, requerirán al titular para que corrija las deficiencias; siendo posible la suspensión cautelar de la actividad (art. 22 y 23-LAC).

Además, la suspensión de la actividad se establece como medida cautelar general, tanto en la construcción de la instalación como en su explotación, si se incumplen las condiciones impuestas para la ejecución del proyecto o si existen razones fundadas de daños graves o irreversibles al medio ambiente, o peligro para las personas o bienes. Asimismo, se reconoce la ejecución subsidiaria por la autoridad que la hubiere requerido, si el titular de la instalación no la ejecutara (arts. 24 y 25 -LAC).

El sistema protector del medio ambiente terminaba con la regulación del régimen sancionador, como típico instrumento de policía administrativa, que cierra el texto legislativo (arts. 27 a 41-LAC). Las competencias sancionadoras las ostentan los Alcaldes, el entonces Consejero de Medio Ambiente y Ordenación del Territorio y la propia Junta de Castilla y León, en función de la calificación de las infracciones y, en particular, de la cuantía de las 
multas; debiendo tenerse en cuenta las normas de la época sobre desconcentración de funciones.

Existiendo otro importante instrumento preventivo regulado en la Comunidad de Castilla y León, como son las Evaluaciones de Impacto Ambiental (reguladas originalmente en 1994), la Disposición Adicional 1º, LAC, permitía eximir del informe de la Comisión de Actividades Clasificadas a los proyectos sometidos a evaluación ambiental, siendo esta última prioritaria, pues, de ser negativa, procederá la denegación de las licencias de actividades clasificadas.

Desde el punto de vista organizativo, el Decreto de aplicación de la Ley, con la modificación de 1998, regula las Comisiones Provinciales y Regional de Actividades Clasificadas, como órganos colegiados autonómicos competentes en la materia. Por su parte, varios Decretos y Órdenes dictados en 1994 y 1995 procedieron a llevar a la práctica la delegación de competencias autonómicas en favor de Municipios, prevista en el art. 6 de la propia Ley.

Por último, en desarrollo de la Disposición Final, $1^{\text {a }}$-LAC, se aprobó el Decreto 3/1995, de 12 de enero, por el que se establecen las condiciones que deberán cumplir las Actividades Clasificadas, por sus Niveles Sonoros o de Vibraciones (BOCYL del 17). Este Decreto somete a sus disposiciones las actividades y dispositivos susceptibles de generar niveles sonoros o de vibraciones que puedan ser causa de molestia a las personas o de riesgos para la salud o el bienestar de los mismos (art. 1). Desde el punto de vista competencial, el Decreto prevé que la mayoría de las funciones las lleven a cabo los Municipios (control, medidas correctoras, limitaciones, desarrollo a través de Ordenanzas, etc.); estando prevista, por subrogación, la intervención de la entonces Consejería de Medio Ambiente y Ordenación del Territorio (arts. 2 y 3). El bloque normativo central del Decreto regula las perturbaciones por ruidos (arts. 5 a 15 , estableciendo las unidades de medida, los niveles de ruido en los ambientes exterior e interior, la valoración de los niveles sonoros, con sus inspecciones y precauciones, el aislamiento acústico de las edificaciones, las condiciones de los servicios y los vehículos de motor), por vibraciones (arts. 16 y 17, regulando la intensidad de percepción de vibraciones y las reglas para corregir la transmisión de las mismas), la documentación requerida en las licencias. (arts. 18 y 19), y el régimen de inspección y sancionador (arts. 20 a 32).

En esta misma línea, y siguiendo el principio preventivo, posteriormente se aprobó la Ley 8/1994, de 24 de junio (BOCYL del 29), de Evaluación de Impacto Ambiental y Auditorias Ambientales, que fue modificada en 1996 y 1998, por lo que se elaboró el Texto Refundido de la Ley, aprobado por Decreto Legislativo 1/2000, de 18 de mayo (BOCYL de 27 de octubre). En desarrollo de estas normas se elaboraron Reglamentos de desarrollo en 1995 y 1999. Estos textos legales y reglamentarios regulan las Evaluaciones de Impacto Ambiental (sobre proyectos de obras concretos, distinguiendo las ordinarias y las simplificadas en función del impacto 
ambiental de las mismas, o si inciden en áreas de sensibilidad ecológica), las Evaluaciones Estratégicas (que evalúan ambientalmente los instrumentos de planificación y programación autonómicos, regulando así de forma pionera un excelente instrumento ambiental preventivo) y las Auditorias Ambientales (para analizar y evaluar ambientalmente toda la actividad de una empresa y proceder a la implantación de sistemas para solucionar los problemas detectados).

\section{C) El modelo actual de prevención ambiental y de control integrado de la contaminación en la Comunidad de Castilla y León: la Ley de Prevención Ambiental de 2003 y sus normas de desarrollo}

\section{1) Aspectos generales, ámbito de aplicación y sistema administrativo de prevención ambiental}

Teniendo en cuenta la reforma del Estatuto de Autonomía de 1999 (que incluye el patrimonio natural entre los valores esenciales de la Comunidad), la adopción el 29 de enero de 1999 de la Estrategia de Desarrollo Sostenible para Castilla y León (que incide en la importancia del principio de integración ambiental), la creación también en 1999 de la Consejería de Medio Ambiente (que se mantiene en la reestructuración de Consejerías de 2003), las nuevas normas europeas y estatales sobre control integrado de la contaminación y sin disminuir la importancia de las normas anteriores, debe destacarse la trascendencia de la elaboración y aprobación de la Ley 11/2003, de 8 de abril, de Prevención Ambiental de Castilla y León (BOCYL del 14), modificada posteriormente por la Ley 13/2003, de 23 de diciembre (BOCYL del 30), la Ley 9/2004, de 28 de diciembre (BOCYL del 31), y la Ley 3/2005, de 23 de mayo (BOCYL del 24).

En desarrollo de la Ley se han aprobado el Decreto 123/2003, de 23 de octubre (BOCYL del 29), modificado por Decreto 81/2005, de 3 de noviembre (BOCYL del 9) y la Orden MAM/ 1648/2003, de 11 de diciembre (BOCYL), que regulan las Comisiones de Prevención Ambiental y sus Ponencias Técnicas, y la Orden MAM/1673/2004, de 26 de octubre (BOCYL de 12 de noviembre), modificada por Orden MAM/678/2005, de 19 de mayo (BOCYL del 27), que designan al personal encargado de realizar las funciones de inspección en esta materia. Además, deben tenerse en cuenta las disposiciones que, en el marco de los procesos de descentralización incluidos en la filosofía de los pactos locales, delegan competencias de prevención ambiental en los Municipios de mayor población de la Comunidad (según lo previsto en la Disposición Adicional única de la Ley).

De acuerdo con su Disposición Derogatoria, la Ley, según la modificación de 2003, procede a derogar la Ley de Actividades Clasificadas de 1993 
y el Texto Refundido de la Ley de Evaluación de impacto Ambiental y Auditorias Ambientales de 2000, salvo las disposiciones relativas a las Evaluaciones Estratégicas y a las propias Auditorias Ambientales, que continúan en vigor en un Texto Refundido ahora verdaderamente escueto en su contenido (utilizando una forma de legislar muy poco comprensible ya que ambos instrumentos, por su carácter preventivo, podían perfectamente haberse incluido en la nueva Ley, y derogar completamente el Texto citado). Por otro lado, el Reglamento de desarrollo de la Ley de Actividades Clasificadas de 1994 y el Reglamento de Evaluación de Impacto Ambiental de 1995 continúan en vigor, en aquello que no resulte incompatible, en tanto no se desarrolle reglamentariamente la nueva Ley (cuestión que varios años después de su aprobación no se ha producido aún).

La nueva Ley se enmarca, según su Exposición de Motivos, en el contexto de nuevas normas e instrumentos de prevención y protección ambiental, como son la Directiva sobre Prevención y Control Integrados de la Contaminación, de 1996, y la Ley 16/2002, de 1 de julio, de Prevención y Control Integrados de la Contaminación (BOE del 2), teniendo en cuenta que su vocación es convertirse en el texto legal esencial del Ordenamiento ambiental de la Comunidad, al establecer el sistema de intervención administrativa de las actividades, instalaciones o proyectos susceptibles de afectar al medio ambiente, con la finalidad de avanzar hacia el desarrollo sostenible.

El objeto de la Ley de Prevención Ambiental es la prevención y el control integrado de la contaminación con la finalidad de alcanzar la máxima protección del medio ambiente en la Comunidad, y establece para ello los correspondientes sistemas de intervención administrativa (art. 1).

Partiendo del reconocimiento, como fundamento del texto y de su aplicación, de los principios de protección del medio ambiente para conseguir una adecuada calidad ambiental, del desarrollo sostenible y de la agilización e integración de los procedimientos administrativos, garantizando la colaboración y coordinación de las Administraciones Públicas, la Ley procede a la implantación de un sistema de intervención administrativa, mediante los procedimientos correspondientes, de acuerdo con el grado de incidencia sobre el medio ambiente, la seguridad y la salud (arts. 1, 2 y 6).

El sistema de protección ambiental establecido se fundamenta en someter a la Ley todas las actividades, instalaciones o proyectos, de titularidad pública o privada, susceptibles de ocasionar molestias significativas, alterar las condiciones de salubridad, causar daños al medio ambiente o producir riesgos para personas o bienes, excluyéndose de su ámbito las instalaciones o partes de las instalaciones utilizadas para la investigación, desarrollo y experimentación de nuevos productos y procesos, y sin perjuicio de las intervenciones que correspondan a la Administración General del Estado en materias de su competencia (art. 3). 
Con un adecuado criterio normativo, y como plasmación del principio de prevención ambiental, la Ley establece las condiciones generales de funcionamiento de las actividades e instalaciones y de ejecución de proyectos, al prescribir que las mismas deben ser proyectadas, utilizadas, mantenidas y controladas de forma que se logren los objetivos de calidad ambiental y de seguridad fijados por la legislación vigente, y que deberán cumplir las condiciones generales de funcionamiento establecidas en el sistema de intervención administrativa, que analizaremos más adelante. Además, los titulares o promotores de las actividades e instalaciones incluidas en su ámbito deberán ejercerlas de acuerdo con los siguientes principios: prevenir la contaminación y su transferencia a otro medio, en especial utilizando las mejores tecnologías disponibles; evitar la producción de residuos o reducirla mediante técnicas de minimización y gestionar correctamente los residuos producidos; utilizar la energía, el agua y las materias primas de forma racional, eficaz y eficiente; procurar la sustitución de todas las materias peligrosas por otras que no lo sean; tomar medidas de prevención de accidentes y de limitación de sus efectos; medidas a adoptar al cesar o suspenderse la actividad para evitar cualquier riesgo de contaminación y para que el lugar de la actividad quede en un estado satisfactorio, de forma que el impacto ambiental sea el mínimo posible respecto al estado inicial en que se hallaba (art. 5).

De acuerdo con las normas europeas y nacionales, así como con la normativa de libertad de acceso a la información ambiental, la Consejería de Medio Ambiente ha de crear un sistema de información en esta materia (incluyendo, entre otros, datos sobre la calidad de los recursos naturales, los objetivos y normas de calidad ambiental, los focos de emisiones, los valores límite de emisión autorizados y las mejores técnicas disponibles); además, los titulares de las instalaciones referidas notificarán anualmente a esa Consejería los datos de emisiones; datos autonómicos que la misma ha de comunicar a la Administración General del Estado, y ésta, a su vez, a la Comisión Europea (art. 8).

El régimen jurídico de la intervención administrativa para la prevención y el control integrado de la contaminación se basa en someter unas actividades e instalaciones a autorización, licencia o comunicación ambiental, y otras al procedimiento de evaluación de impacto ambiental, en función del grado de incidencia sobre el medio ambiente, la seguridad y la salud; y sin eximirlas de la obtención de otras autorizaciones o licencias exigibles de acuerdo con la Legislación sectorial aplicable (arts. 6 y 9).

\section{2) El régimen jurídico de la Autorización Ambiental (arts. 10 a 23).}

La Autorización Ambiental, que es la denominada «permiso integrado» en la terminología europea y «autorización ambiental integrada» según la ley 
nacional, se exige a los proyectos e instalaciones, considerados como nueva actividad, recogidos en los Anexos I de esta Ley regional y de la Ley estatal citada, que incluyen a aquellos que tienen un gran impacto en el medio ambiente (y que hacen referencia, en general, a instalaciones energéticas de combustión, instalaciones relativas a la producción y transformación de metales, industrias minerales, industrias químicas, gestión de residuos, industria del papel y cartón, industria textil o del cuero, industrias agroalimentarias y explotaciones ganaderas, consumo de disolventes orgánicos, ciertas instalaciones de fabricación de carbono y fabricación de neumáticos y vehículos automóviles).

Esta autorización refleja, de forma visible, la filosofía ambiental preventiva y los nuevos sistemas de control integrado de la contaminación, y tiene por finalidad, además de la prevista en la Ley nacional citada (que ya hace referencia a tal filosofía), el establecimiento de un sistema administrativo que integre en una autorización única las autorizaciones sectoriales en materia de vertidos de aguas residuales, residuos y emisiones a la atmósfera, y la inclusión de las actuaciones sobre control de riesgos inherentes a los accidentes graves en que intervengan sustancias peligrosas. En el mismo, y adecuado, sentido, la Ley establece que esta autorización precederá a las demás autorizaciones sustantivas o licencias que sean obligatorias. Finalmente, la misma se otorgará sin perjuicio de las autorizaciones o concesiones exigibles conforme a la legislación básica del Estado y otra normativa de aplicación.

El procedimiento de otorgamiento de la Autorización Ambiental se inicia con la solicitud que se presenta ante la Delegación Territorial de la Junta de Castilla y León de la provincia en que se pretenda implantar la actividad o realizar la actuación (adjuntando, además de la documentación exigida por la Legislación nacional, el proyecto básico, el estudio de impacto ambiental, si procede, y cualquier otra documentación exigida). Seguidamente se deben incorporar diversos informes (entre ellos, los que han de emitir los Ayuntamientos respectivos sobre cuestiones urbanísticas, que, en este caso, si es negativo, el procedimiento no continua, y otros sobre aspectos de su competencia, así como los informes del Organismo de Cuenca y de otros órganos con competencias en la materia), y proceder a los trámites de información pública y audiencia a los interesados. Con todo ello, y en su caso de la evaluación de impacto ambiental, las Comisiones de Prevención Ambiental (Territorial y Regional, según los casos) elaboran el proyecto de resolución, y, si procede, la propuesta de declaración de impacto ambiental, resolviendo, finalmente, en el plazo de diez meses, con silencio administrativo negativo, el Consejero de Medio Ambiente. La resolución debe ser notificada a los interesados, a los Ayuntamientos donde se ubique la instalación, a los órganos que hubiesen emitido informes vinculantes y a los demás órganos que deban otorgar autorizaciones preceptivas, y publicada en el BOCYL.

No obstante, de acuerdo con la reforma de la Ley de Prevención Ambiental de 2005, con carácter excepcional, cuando se trate de Proyectos Regionales 
regulados en la Ley de Ordenación del Territorio de 1998 cuya declaración se lleve a cabo por una Ley específica, ésta misma podrá resolver la autorización ambiental; en cuyo caso, la aprobación del Proyecto mediante Ley implicará la inmediata aptitud para el funcionamiento de las infraestructuras, servicios, dotaciones e instalaciones referidas, siguiendo el procedimiento establecido en la Ley de Prevención Ambiental, salvo que la Ley específica de aprobación del Proyecto Regional y concesión de la autorización ambiental disponga otra cosa.

\section{3) El sistema de la Licencia Ambiental (arts. 24 a 32)}

Seguidamente, la Ley regula la Licencia Ambiental, a la que se deben someter las actividades e instalaciones que ocasionen molestias considerables, de acuerdo con la normativa aplicable, alteren las condiciones de salubridad, causen daños al medio ambiente o produzcan riesgos a las personas o bienes; excluyéndose las sometidas tanto a autorización ambiental (que es la única mención del art. 24), como a comunicación ambiental.

La finalidad de la licencia ambiental es regular y controlar las actividades e instalaciones para prevenir y reducir en origen las emisiones a la atmósfera, al agua y al suelo que produzcan las mismas, incorporar a dichas actividades las mejoras técnicas disponibles validadas por la Unión Europea y establecer las condiciones para una correcta gestión de ésas emisiones.

El procedimiento administrativo de la licencia ambiental se inicia con la solicitud de la misma ante el Ayuntamiento en cuyo término municipal se pretenda emplazar la actividad o instalación, acompañándola del proyecto básico (redactado por técnico competente e incluyendo datos de la instalación, de sus emisiones y fuentes, de la incidencia ambiental, de la justificación del cumplimiento de la normativa sectorial, de las técnicas de prevención, control y reducción de emisiones, de las medidas de gestión de los residuos y de otras medidas correctoras), si bien el mismo puede ser sustituido por una memoria si lo permite la normativa sectorial; de las autorizaciones previas exigibles; de la declaración de los datos confidenciales de acuerdo con la legislación aplicable; de cualquier otra exigible reglamentariamente, y de un resumen o memoria de la documentación formulado de forma comprensible.

Salvo que proceda la denegación expresa de la licencia por el Ayuntamiento, debido a razones de competencia municipal (basadas en el planeamiento urbanístico, en las ordenanzas municipales o por el incumplimiento de requisitos exigidos por la legislación sectorial), seguidamente, debe abrirse un período de información pública (por veinte días, con publicación del anuncio en el Boletín Oficial de la Provincia y el tablón de anuncios del Ayuntamiento) y debe procederse a dar audiencia a los vecinos inmediatos al lu- 
gar de la instalación y a los que pudieran verse afectados; para someterse el expediente (incluyendo un informe razonado del Ayuntamiento sobre las alegaciones), posteriormente, a la Comisión de Prevención Ambiental que resulte competente, cuyo informe será vinculante para el Ayuntamiento, si es denegatorio de la licencia o impone medidas correctoras, devolviendo el expediente al Ayuntamiento para que resuelva, con audiencia previa a los interesados; si bien, en caso de que fuera necesario, la Comisión citada puede solicitar más informes a otros órganos de la Administración autonómica, que se entenderán favorables si no fuesen emitidos en quince días.

La resolución sobre la concesión de la licencia ambiental corresponde al Alcalde, que pone fin a la vía administrativa, en un plazo de cuatro meses; transcurridos los cuales se entenderá estimada la misma por silencio positivo, sin que puedan generarse, en este caso, facultades o derechos contrarios al ordenamiento jurídico y, particularmente, sobre el dominio público. La resolución sobre la licencia, cuando sea expresa, ha de incluir las prescripciones de protección del medio ambiente, los valores límite de emisión y las medidas de control, seguridad y preventivas procedentes. En caso de que el proyecto deba someterse a evaluación de impacto ambiental, el Alcalde, al conceder la licencia ambiental, debe recoger las condiciones de la previa declaración de impacto ambiental. La resolución estimatoria o denegatoria de la licencia ambiental debe notificarse a los interesados y dar traslado de la misma a la Comisión de Prevención Ambiental correspondiente.

En el supuesto de que, además de la licencia ambiental, una actividad o instalación requiera también la licencia urbanística, ambas deben ser objeto de una resolución única por el Ayuntamiento respectivo, sin perjuicio de su tramitación separada; pero el otorgamiento de la licencia ambiental es requisito previo para la concesión de la licencia urbanística, y, por tanto, si se deniega la primera no se puede conceder la licencia urbanística. Si además se requiere autorización de uso excepcional en suelo rústico, la misma es previa al otorgamiento de las licencias ambiental y urbanística. Dicha autorización corresponde otorgarla a los Ayuntamientos, en los Municipios con población igual o superior a 20.000 habitantes o que cuenten con Plan General de Ordenación Urbana adaptado a la Ley de Urbanismo de Castilla y León de 1999; en el resto de los Municipios, corresponde a la Comisión Territorial de Urbanismo.

La Ley establece la exención del trámite de calificación e informe por las Comisiones de Prevención Ambiental de las instalaciones y actividades incluidas en el Anexo II (y que van desde talleres variados, determinadas actividades industriales, ciertas instalaciones pecuarias o determinadas actividades de almacenamiento agrícola hasta garajes comerciales, actividades comerciales y de servicios, actividades de hostelería o puntos limpios y plantas de transferencia de residuos urbanos; las cuales, materialmente, parecen tener una menor incidencia en el medio ambiente), sin perjuicio de la aplicación del resto de la Ley. 


\section{4) Disposiciones comunes a la autorización ambiental y a la licencia ambiental (arts. 33 a 44)}

En ambos supuestos, con carácter previo al inicio de las actividades correspondientes, la Ley exige que la Administración Pública competente conceda la autorización de puesta en marcha de las mismas; que, en el caso de la autorización ambiental, se denomina autorización de inicio de la actividad y concede la Consejería de Medio Ambiente, y que, en el caso de la licencia ambiental, se denomina licencia de apertura, y concede el Alcalde competente; siendo posible su concesión por silencio positivo (por el transcurso de dos o de un mes, respectivamente), aunque la misma, así concedida, no permite la adquisición de facultades en contra de la legislación aplicable o de la propia autorización o licencia. En estos períodos, la Administración competente debe realizar las actividades de control y verificación generales (relativas a la adecuación de la actividad al proyecto y el cumplimiento de los requisitos exigibles); levantándose la correspondiente acta de comprobación de las instalaciones. Ambas han de concederse previamente a las autorizaciones de suministros de servicios públicos (agua, energía eléctrica, combustibles, etc.), aunque son posibles autorizaciones provisionales para la realización de las pruebas necesarias para comprobar el funcionamiento de la actividad.

No obstante, el titular de la autorización o de la licencia está obligado a informar al órgano autonómico o al Ayuntamiento respectivo de cualquier cambio en las condiciones de concesión de las mismas, sus características o sobre el funcionamiento de la instalación.

Las autorizaciones ambientales, en todo caso, y aquellas licencias ambientales que se determinen reglamentariamente se otorgan por un plazo de ocho años; transcurridos los cuales han de ser renovadas y actualizadas por períodos sucesivos (sin derecho a indemnización alguna), previa solicitud y mediante un procedimiento simplificado, que ha de ser establecido reglamentariamente, cuya resolución podrá modificar los valores límites de emisión y otras condiciones de las mismas. Además, la Ley permite la modificación de oficio (también sin derecho a indemnización alguno) de las autorizaciones y licencias en determinados supuestos (contaminación producida, variaciones en el medio, seguridad de funcionamiento, circunstancias relativas al agua o exigencias de la legislación sectorial); que se tramitarán, igualmente, por un procedimiento simplificado a establecer reglamentariamente. Asimismo, la Ley prevé la revisión de oficio y la caducidad de tales autorizaciones y licencias. Finalmente, se permite la transmisión de las actividades o instalaciones con autorización o licencia, si bien se exige la comunicación de la misma a la Consejería de Medio Ambiente o al Ayuntamiento respectivo (estableciendo la responsabilidad correspondiente en caso de no producirse la misma); subrogándose el nuevo titular en todos los derechos, obligaciones y responsabilidades del anterior, respondiendo ambos solidariamente de las obligaciones preexistentes. 


\section{5) El régimen de las Evaluaciones de Impacto Ambiental (arts. 45 a 57)}

Respecto a las Evaluaciones de Impacto Ambiental, como instrumento de valoración de los efectos sobre el medio ambiente de determinados proyectos de obras, la nueva Ley ratifica el sistema de las Leyes de 1994 y 2000, citadas. Así, se distinguen dos tipos de proyectos de obras (en los Anexos III y IV de la Ley), y los incluidos en la legislación básica, que deben someterse a un procedimiento de evaluación ambiental, así como sus modificaciones, ampliaciones y reformas; si bien, la Junta de Castilla y León puede excepcionar algunos proyectos mediante acuerdo motivado, y que ha de publicarse. Esta distinción se justifica en el mayor (Anexo III) o menor (Anexo IV) impacto ambiental de los proyectos que se incluyen, y que en las Leyes de 1994 y 2000 , ya derogadas, se preveían y se remitía su evaluación ambiental a un procedimiento ordinario y simplificado respectivamente (siguiendo la premisa administrativa, con mucho sentido común por otra parte, de que a un proyecto de mayor impacto ambiental le corresponde un procedimiento completo y al menor impacto un procedimiento simplificado); denominaciones que la nueva Ley no asume, si bien sustantivamente la misma distinción y justificación es visible.

Los proyectos de obras deben someterse a un procedimiento de evaluación ambiental, que ha de incluir la elaboración de un estudio de impacto ambiental (en el que deben reflejarse todos los datos que permitan la evaluación: descripción del proyecto, medios afectados, impactos, medidas correctoras, alternativas, etc., y un resumen no técnico), sometiéndose la solicitud y el estudio a trámite de información pública, con lo que se procede a elaborar la declaración de impacto ambiental (que determina, a los solos efectos ambientales, sobre la conveniencia o no de ejecutar el proyecto, y, en caso afirmativo, fijará las condiciones en que debe realizarse), que será dictada por el Delegado Territorial de la Junta (respecto a los proyectos del Anexo IV) o el Consejero de Medio Ambiente (en relación con los proyectos del Anexo III). Si hay discrepancias entre el órgano sustantivo (es decir, el competente sobre el proyecto) y el órgano ambiental, debe resolver la Junta de Castilla y León. La declaración de impacto ambiental se notifica a los interesados y se publica en el BOCYL.

Además, se prevén medidas de vigilancia ambiental que corresponden a los órganos sustantivos, otras de coordinación con la Administración General del Estado y medidas cautelares de suspensión de proyectos y actividades que no se sometan a evaluación ambiental (siendo obligatorias las mismas).

\section{6) El novedoso sistema de Comunicación Ambiental (art. 58)}

En último lugar, en el sistema de intervención administrativa, la nueva Ley regula la Comunicación Ambiental. Este sistema se utiliza únicamente para 
las actividades incluidas en el Anexo V de la Ley, y cuya característica es que tienen la menor incidencia ambiental (y que se refieren, entre otros, a diversos talleres, instalaciones de cría de perros, dispositivos sonoros para ahuyentar pájaros en agricultura, instalaciones de energía en viviendas, garajes de vehículos no comerciales, centros de turismo rural, oficinas y edificios administrativos, centros de enseñanza, música o baile, residencias de personas mayores o guarderías infantiles). Esta menor incidencia ambiental de estos proyectos justifica y se refleja en la exigencia de un régimen jurídico y un procedimiento administrativo muy sencillos: únicamente se exige la comunicación previa del ejercicio de tales actividades al Ayuntamiento respectivo, o su modificación, sin perjuicio de la aplicación de la propia Ley y de la normativa sectorial. La documentación exigible debe precisarse reglamentariamente o mediante ordenanza municipal.

No obstante, los Ayuntamientos pueden sustituir este régimen de comunicación ambiental por el establecimiento de la exigencia de la licencia ambiental (para esas mismas actividades del Anexo V), que se tramita y resuelve simultáneamente con la licencia urbanística, cuando sea preceptiva; para lo cual el Ayuntamiento debe aprobar una ordenanza o un reglamento, precisando las actividades, la documentación, la información pública y vecinal. En este sentido, a título de ejemplo, puede citarse, entre otras, la Ordenanza Municipal sobre Prevención Ambiental del Ayuntamiento de Salamanca, de 6 de noviembre de 2003 (Boletín Oficial de la Provincia del 26).

\section{7) El régimen de control, de inspección y sancionador (arts. 59 a 68 y 73 a 88 )}

De forma adecuada, la Ley de Prevención Ambiental prevé que las autorizaciones y licencias ambientales han de establecer sistemas de control sobre la actividad referida, con la finalidad de garantizar su adecuación a la normativa aplicable; remitiéndose al desarrollo reglamentario la regulación de los sistemas de verificación y control periódico de las actividades por parte de las Administraciones Públicas competentes.

La inspección de las actividades e instalaciones sujetas a autorización ambiental corresponde a la Consejería de Medio Ambiente (teniendo los Ayuntamientos la obligación de notificar a ésta las deficiencias detectadas) y la del resto es responsabilidad del Ayuntamiento respectivo, sin perjuicio de las que puedan ostentar otros órganos por razón de la materia. Además, la alta inspección en la materia también corresponde a la Consejería de Medio Ambiente, así como la actuación subsidiaria en los casos de inactividad de los Ayuntamientos.

La Ley regula el régimen de actuación en caso de denuncia de deficiencias del funcionamiento de las instalaciones y de comunicación por los titu- 
lares de irregularidades en el funcionamiento de las mismas; con previsión expresa de la eventual suspensión de actividades, ejecución de medidas correctoras y, si es el caso, de regularización de actividades realizadas sin autorización o licencia.

Siguiendo el modelo de otras leyes, se regula el personal designado para realizar las funciones inspectoras, con la consideración de agentes de autoridad (cuyo desarrollo se ha llevado a cabo mediante Orden MAM/1673/2004, de 26 de octubre, BOCYL del 12 de noviembre, modificada mediante Orden MAM/678/2005, de 19 de mayo, BOCYL del 27), su actividad inspectora (acceso a instalaciones, actas de inspección, etc.) y se reconoce el carácter público de sus resultados.

El texto de la Ley finaliza, como es habitual, con la regulación del régimen sancionador, reconociendo la acción pública y estableciendo las infracciones, la responsabilidad, las sanciones correspondientes (con su graduación y su posible concurrencia), la competencia sancionadora, la prescripción de unas y otras, el procedimiento sancionador, las medidas restauradoras de la legalidad, las medidas provisionales, los supuestos de inactividad de las Corporaciones Locales, el uso de multas coercitivas y de la vía de apremio, así como la previsión de que las infracciones sean constitutivas de delito o falta penal.

\section{8) Las Comisiones de Prevención Ambiental (arts. 69 a 72)}

Esta parte orgánica de la Ley se ha desarrollado mediante Decreto 123/ 2003, de 23 de octubre (BOCYL del 29), modificado por Decreto 81/2005, de 3 de noviembre (BOCYL del 9), que regulan la composición y funcionamiento de las Comisiones de Prevención Ambiental, y por Orden MAM/1648/ 2003, de 11 de diciembre (BOCYL del 19), que establece la composición de la Ponencia Técnica de las mismas.

Las Comisiones Territoriales de Prevención Ambiental son órganos administrativos colegiados, de ámbito provincial, adscritas a la Consejería de Medio Ambiente, con funciones de emitir informes y formular propuestas en relación con expedientes de instalación, ampliación o reforma de las actividades, proyectos o instalaciones a las que se refiere la propia Ley y evaluaciones de impacto ambiental, cuando así se establezca. Más en concreto, a estas Comisiones le corresponde la formulación de la propuesta de resolución en los procedimientos de instalación, ampliación o reforma de actividades o instalaciones sometidas al régimen de autorización ambiental; informar preceptivamente los mismos expedientes de actividades o instalaciones sometidas a licencia ambiental (salvo que los mismos deban ser sometidos a evaluación de impacto ambiental); formular la propuesta de declaración de impacto ambiental de los proyectos sometidos a esta legislación y la relativa al sometimiento a este procedimiento según la Legislación básica estatal 
ante la Consejería de Medio Ambiente; proponer a los Alcaldes las medidas correctoras de las actividades que se desarrollen en su término municipal, cuando las circunstancias lo aconsejen, y aquellas que le encomiende la Consejería de Medio Ambiente, relacionadas con las anteriores, y aquellas otras funciones que le sean atribuidas por la normativa sectorial.

Como órganos colegiados, bajo la presidencia del correspondiente Delegado Territorial de la Junta de Castilla y León, se componen de varios vocales de la Administración autonómica, de la Diputación Provincial, de los Municipios, de la Administración General del Estado y de organizaciones empresariales, sindicales, agrarias y de las Cámaras de Comercio e Industria. Respecto a su funcionamiento, no hay novedades resaltables salvo que, cuando el Delegado Territorial sea el órgano resolutorio en el expediente correspondiente, el mismo no participará en la adopción del acuerdo, ejerciendo como presidente el vicepresidente de la misma (que es el Jefe del Servicio Territorial de Medio Ambiente). Como órgano de asesoramiento, apoyo y asistencia de cada Comisión, existe en cada provincia una Ponencia Técnica, presidida por el Jefe del Servicio Territorial de Medio Ambiente y compuesta por vocales, en su mayoría, de la Administración regional, de la Diputación Provincial y de la Administración estatal.

La Comisión de Prevención Ambiental de Castilla y León es el órgano colegiado superior en esta materia, también, adscrito a la Consejería de Medio Ambiente. Sus funciones son la formulación de las propuestas de resolución de las autorizaciones y licencias ambientales cuando tales actividades o instalaciones superen el ámbito provincial; formular la propuesta de declaración de impacto ambiental, tanto según la legislación propia como según la normativa básica, cuando los proyectos afecten a más de una provincia o se considere oportuno; orientar y homogeneizar los criterios y actividades de las Comisiones Territoriales; emitir informes en estas materias que le sean requeridos por la Consejería citada o cuando lo exija la legislación vigente, y evacuar las consultas de las Comisiones Territoriales o de cualquier otro órgano de la Administración regional.

Bajo la presidencia del Secretario General de la Consejería de Medio Ambiente, incluye también una composición variada (de las Administraciones regional, local, estatal, y de las organizaciones empresariales, sindicales, etc., de ámbito autonómico) y con un mayor nivel administrativo o directivo que el de las anteriores. Como órganos de asesoramiento, igualmente, se prevén las Ponencias Técnicas, en los casos establecidos en las normas citadas.

\section{9) El régimen excepcional de las actividades ganaderas en Castilla y León}

En su inicio, hace ya bastantes años, la actividad agroganadera contribuía, y así se consideraba en general, a la preservación de los recursos naturales, 
e incluso los mejoraba; considerándose que los agricultores y los ganaderos han desarrollado un papel trascendental en la conservación del suelo y en la conservación de la naturaleza.

El necesario aumento de las producciones (bien visible en la Comunidad Europea desde hace cuarenta años) ha propiciado una evolución de estas actividades hacia una mayor tecnificación e intensificación de la misma, incluyendo una fuerte concentración de actividades, con una especialización geográfica acusada, y separándose (no siempre) la producción agraria de la ganadera. Todo ello ha traído consigo el uso, y a veces el abuso, de sustancias químicas ajenas a la actividad agroganadera (principalmente, plaguicidas y fertilizantes), y sobrecarga de productos orgánicos sobrantes; poniéndose en cierto peligro la propia fertilidad de los suelos a largo plazo. Además, las explotaciones ganaderas generan otros problemas ambientales, además de los relativos al suelo, tales como momentáneas contaminaciones del aire, malos olores, problemas sanitarios, impacto sobre el paisaje y otros (como ruidos, residuos zoosanitarios, cadáveres de animales o atracción y generación de insectos).

La normativa española de protección y prevención ambiental y sobre actividades clasificadas tiene un antecedente directo en la importante legislación sanitaria y municipal que se promulgó a partir del siglo XIX, e incluso antes. Pero, teniendo en cuenta la importancia socioeconómica que las actividades agroganaderas han supuesto siempre en España, las normas reguladoras han sido en general muy flexibles en relación con la ubicación de tales explotaciones, dejando casi siempre tales decisiones a las autoridades municipales (si bien ya se preveía su traslado fuera de las poblaciones, como en las conocidas Ordenanzas de Policía Urbana y Rural para la villa de Madrid y su término, de 16 de noviembre de 1847). Posteriormente, y fruto del incipiente desarrollo socioeconómico de la época, el RAMINP de 1961 incluye la actividad ganadera en su ámbito de aplicación, remitiendo su emplazamiento a las Ordenanzas municipales y a los Planes Urbanísticos, estableciendo medidas correctoras y prohibiendo absolutamente las vaquerías, establos, cuadras y corrales de ganado y aves en los núcleos urbanos de Municipios con más de 10.000 habitantes, concediéndose un plazo de diez años para su desaparición, así como limitaciones relativas a distancias respecto a las actividades insalubres.

Teniendo la Comunidad de Castilla y León una clara vocación agroganadera, pronto se plantearán los problemas ambientales, y sanitarios, de estas actividades, en particular en los pequeños Municipios.

No obstante, la Ley de Actividades Clasificadas de 1993 no recogió las prohibiciones del RAMINP respecto a las distancias de emplazamientos de las mismas, respecto a los núcleos de población; es más, algunas actividades, de pequeña envergadura, se consideraron exentas. Además, se produjeron ciertos desajustes por la incidencia de la normativa urbanística. 
En este contexto, y fruto de una Proposición de Ley presentada en las Cortes de Castilla y León por el Grupo Parlamentario Popular (Pp. L. n ${ }^{\circ} 16-$ I, BOCCYL n ${ }^{\circ} 151$, de 5 de abril de 2005), se elaboró y aprobó la Ley 5/ 2005, de 24 de mayo, de establecimiento de un Régimen Excepcional y Transitorio para las Explotaciones Ganaderas en Castilla y León (BOCYL del 26).

La nueva Ley establece un régimen excepcional y transitorio (principalmente en los Municipios con menos de 2.500 habitantes, si bien, en algunos casos, puede no aplicarse, y con matices en los que superen tal número) para la concesión de la licencia ambiental de las explotaciones ganaderas, con ciertas condiciones (entre otros, no estar sometidas a evaluación de impacto ambiental, haber iniciado su actividad con anterioridad a la Ley, encontrarse en disconformidad con la normativa urbanística y no superar los límites de capacidad fijados). Para la regularización de estas actividades, la Ley establece un procedimiento administrativo que ha de iniciarse en el plazo de dos años (a contar desde el 27 de mayo de 2005), previa petición del titular de la explotación ante el Ayuntamiento respectivo, con trámites de información pública y audiencia, informe de la Delegación Territorial de la Junta (si se superan ciertos límites) y resolución final sobre el expediente por el Alcalde respectivo, en un plazo de doce meses desde la solicitud, con silencio administrativo negativo. Además, la Ley regula el régimen de la licencia ambiental (medidas correctoras, plazo de 16 años, cambios en la explotación, transmisión de la misma, etc.).

\section{BIBLIOGRAFÍA BÁSICA}

Alonso García, E., y Lozano Cutanda, B., Diccionario de Derecho Ambiental, Ed. Iustel, Madrid, 2005.

Artiñano del Río, P., y MuÑoz FernándeZ, S., La protección municipal del medio ambiente. La licencia de actividades clasificadas, Ed. La Ley-Actualidad, Madrid, 1998.

Cano Murcia, A., Manual de Licencias de Apertura de Establecimientos, $4^{\mathrm{a}}$ ed., Ed. Thomson-Aranzadi, Cizur Menor (Navarra), 2005.

De la Morena y de la Morena, L.: «Las potestades de intervención de los municipios en materia de actividades clasificadas», El Consultor, $\mathrm{n}^{\circ}$ 7, 15 de abril de 1998.

- «Las Potestades de inspección y de sanción de los Municipios en materia de actividades clasificadas, según la jurisprudencia», El Consultor, $\mathrm{n}^{\circ}$ 10, 30 de mayo de 1998.

DOMPER FERRANDO, J., El medio ambiente y la intervención administrativa en las actividades clasificadas, 2 tomos, Ed. Civitas, Madrid, 1992. 
Esteve Pardo, J., Derecho del Medio Ambiente, Ed. M. Pons, Madrid, 2005.

FERNÁNDEZ DE GATTA SÁNCHEZ, D.: «Los problemas de coordinación de las actividades sectoriales sobre el territorio, con especial referencia a Castilla y León», Revista de Derecho Urbanístico, no 144 /1995.

- «La Ley de Actividades Clasificadas: un importante instrumento para la protección del medio ambiente en Castilla y León», Revista Medio Ambiente en Castilla y León, no 8/1997.

- «Las competencias de la Comunidad de Castilla y León en materia de Medio Ambiente», en VARIOS Autores, Estudios de Derecho y Gestión Ambiental, Tomo II, Ed. Fund. Cultural Sta. Teresa y Junta de Castilla y León, Ávila, 1999.

- «El régimen jurídico del control integrado de la contaminación», Revista de Derecho Ambiental, no 22/1999.

- «La Ley de Actividades Clasificadas de Castilla y León», en VARIOS AUTORES, El Derecho Administrativo en el umbral del siglo XXI. Homenaje al Prof. Dr. D. Ramón Martín Mateo, Tomo III, Ed. Tirant Lo Blanch, Universidad de Alicante y Generalidad Valenciana, Valencia, 2000.

- y PÉrez Alenchrt, A., Manual del Alcalde, 2a ed. ampliada, Ed. Diputación de Valladolid y Universidad de Salamanca, Valladolid, 2004.

- «La Protección Jurídica del Medio Ambiente: evolución y perspectiva general», en Gómez-Heras, J. Ma ., y Velayos, C. (Coords.), y otros, Tomarse en serio la Naturaleza. Ética ambiental en perspectiva multidisciplinar, Ed. Biblioteca Nueva, Madrid, 2004.

- «Derecho Ambiental: Aspectos Generales sobre la Protección Jurídica del Medio Ambiente», en e-Derecho Administrativo, no 12/2004 http:// www.usuarios.lycos.es/edea/2004/numero12/ambiental.htm

FERNÁNDEZ RodRÍGUEZ, T. R., El medio ambiente urbano y las vecindades industriales, Ed. IEAL, Madrid, 1973.

Fuentes Bodelón, F., El nuevo régimen de licencias en la Directiva 96/61 sobre prevención y control integrado de la contaminación, Ed. Comares, Granada, 1999.

LóPez-JurAdo, F. de B., y RuIZ DE ApodACA, A., La autorización ambiental integrada. Estudio sistemático de la Ley 16/2002, de prevención y control integrados de la contaminación, Ed. Civitas, Madrid, 2002.

Lozano Cutanda, B., Derecho Ambiental Administrativo, $6^{\mathrm{a}}$ ed., Ed. Dykinson, Madrid, 2005.

Lozano Cutanda, B., y Alli Turrillas, J. C., Administración y Legislación Ambiental, Ed. Dykinson, Madrid, 2005. 
EL RÉGIMEN JURÍDICO DE LA PREVENCIÓN AMBIENTAL EN LA COMUNIDAD DE CASTILLA Y LEÓN

MACERA, B.F., El deber industrial de respetar el ambiente. Análisis de una situación pasiva de Derecho Público», Ed. M. Pons, Madrid 1998.

Martín Mateo, R.: Derecho Ambiental, Ed. Instituto de Estudios de Administración Local, Madrid, 1977.

- Manual de Derecho Ambiental, 4ª ed., Ed. Thomson - Aranzadi, Cizur Menor (Navarra), 2005.

- Tratado de Derecho Ambiental, 3 Tomos, Ed. Trivium, Madrid, 1991, 1992 y 1997, IV Tomo, Ed. Edisofer, Madrid, 2003.

Plaza Martín, C., Derecho Ambiental de la Unión Europea, Ed. Tirant Lo Blanch, Valencia, 2005.

Quintana López, T. (Dir.), Fdez. De Gatta Sánchez, D., y otros, Derecho Ambiental en Castilla y León, Ed. Consejería de Medio Ambiente (J. C. y L.)-Tirant Lo Blanch, Valencia, 2003.

Revuelta PÉRez, I., El control integrado de la contaminación en el Derecho Español, Ed. M. Pons, Madrid, 2003.

Segura, M., Actividades estructuradas, Ed. Bosch, Barcelona, 1963.

Trujillo PEÑA, J., Régimen jurídico en las actividades molestas, insalubres, nocivas y peligrosas, Ed. Santillana, Madrid, 1967.

VAlencia Martín, G., «Aplicación y perspectivas de futuro de la Directiva sobre prevención y control integrados de la contaminación», Noticias de la Unión Europea, no 190/2000.

VARIOS AUTORES, Estudios de Derecho y Gestión Ambiental, Ed. Fundación Cultural Santa Teresa y Consejería de Medio Ambiente y Ordenación del Territorio (J.C. y L.), Ávila, 1999.

Vega JuRAdo, D., La disciplina ambiental de las actividades industriales, Ed.Tecnos, Madrid, 1994.

Recopilación de Normativa Ambiental de la Comunidad de Castilla y León, Consejería de Medio Ambiente (JCyL), Valladolid, 2004 (actualizado).

Legislación ambiental de la Comunidad Autónoma de Castilla y León, Dir. T. Quintana López, 2a ed., Ed. Tirant lo Blanch, Valencia, 2005.

Código de Medio Ambiente, Ed. Thomson - Aranzadi, Cizur Menor (Navarra), 2005. 